\title{
GUÍA DE IDENTIFICACIÓN DE LOS MURCIÉLAGOS DE LA ESPAÑOLA Y ANOTACIONES SOBRE LAS FAMILIAS Y ESPECIES
}

\section{Identification guide of Hispaniola bats with notes on families and species}

\author{
Miguel S. Núñez-Novas ${ }^{1,2,3}$, Rosanna Guzmán-Pérez ${ }^{3}$ y Alexandra Contreras-Puigbó3
}

\author{
${ }^{1}$ Museo Nacional de Historia Natural "Profesor Eugenio de Jesús Marcano". Calle César Nicolás Penson, \\ Plaza de la Cultura Juan Pablo Duarte, Santo Domingo.m.nunez@mnhn.gov.do. \\ ${ }^{2}$ Departamento de Biodiversidad, Ecología y Evolución, Facultad de Biología, Universidad Complutense de Madrid, \\ 28040 Madrid, España. \\ ${ }^{3}$ Universidad Autónoma de Santo Domingo, Escuela de Biología, Edificio de Alta Tecnología, \\ Ciudad Universitaria, Santo Domingo. rosannaguzmanperez24@gmail.com, acpuigbo@gmail.com.
}

\section{RESUMEN}

Se presenta una guía ilustrada de identificación de los quirópteros de La Española, basada en diez años de trabajo de campo y laboratorio. Se incluyen dos claves dicotómicas, una de las familias y otra de las especies, ambas respaldadas ampliamente por figuras y fotografías que ayudarán a la determinación de los táxones, así como del sexo, la madurez sexual y las estructuras más comunes de los murciélagos. Se consideran también varias claves publicadas previamente. En total, son consideradas 18 especies, distribuidas en las seis familias reconocidas para la isla: Noctilionidae, Phyllostomidae, Molossidae, Mormoopidae, Natalidae y Vespertilionidae. Se registran datos importantes sobre la ecología y distribución de las especies incluidas.

Palabras clave: claves dicotómicas, sexo, Molossidae, Mormoopidae, Natalidae, Noctilionidae, Phyllostomidae, Vespertilionidae, Hispaniola.

\section{ABSTRACT}

An illustrated identification guide of the chiropters of Hispaniola, based on 10 years of field and laboratory work is presented, while several keys previously published are considered. Two dichotomic keys are included, one for families and one for species, both suplemented by figures and photographs that will aid in the determination of taxa, sex, sexual maturity, and common structures of the chiropters or bats. 18 species are considered, distributed in the six families recognized for the island: Noctilionidae, Phyllostomidae, Molossidae, Mormoopidae, Natalidae, and Vespertilionidae. Important data on the ecology and distribution of these species is included.

Keywords: dicotomic keys, sex, Molossidae, Mormoopidae, Natalidae, Noctilionidae, Phyllostomidae, Vespertilionidae, Hispaniola.

\section{INTRODUCCIÓN}

Las Antillas constituyen una región zoogeográfica singular dentro del neotrópico. Sin embargo, debido a su ubicación geográfica y reducido tamaño, sus islas presentan una baja diversidad, y riqueza de familias y géneros; pero niveles de endemismo muy altos a nivel específicos, alcanzando hasta un 50\% con relación a los murciélagos (Baker y Genoways, 1978; Rodríguez Durán y Kunz, 2001; Simmons, 2005). 
En las Antillas Mayores, el 73\% de las especies de mamíferos vivientes son murciélagos (Silva-Taboada, 1979). En La Española, los murciélagos constituyen más del 90\% de los mamíferos, distribuidos en 6 familias, 17 géneros y 20 especies (Núñez-Novas y León, 2011, Soto-Centeno et al., 2017). Los murciélagos de la Española han sido objeto de observación desde antes de la llegada de los europeos a finales del siglo XV: los taínos los consideraban animales sagrados (Cassá, 1974). Sin embargo, es a finales del siglo XIX cuando aparecen los primeros reportes de especies que en su mayoría corresponden a la descripción de nuevas especies y localidades (Gundlach, 1877; Elliot, 1905; Allen, 1908; Allen, 1911, 1917; Miller, 1918, 1929, 1930).

En las últimas décadas se siguen realizando citas de nuevas localidades, aunque también se efectúan revisiones taxonómicas, análisis regionales biogeográficos y zoográficos de las distintas especies (Hershkovitz, 1951; Simpson, 1956; Varona, 1974; Baker y Genoways, 1978; Klingener et al., 1978; Fleming, 1982; Koopman, 1989; McFarlane, 1989, 1991; Rodríguez Durán y Kunz, 2001; Dávalos, 2004, 2005, 2010; Tejedor et al., 2005a, 2005b, Goldberg et al., 2010; Núñez- Novas, 2010; Núñez-Novas y León, 2011; Velazco et al., 2013; Núñez-Novas et al., 2014, 2016; Soto-Centeno et al., 2015; Soto-Centeno y Steadman, 2015; Lim et al., 2017; Soto-Centeno et al., 2017; Dávalos et al., 2018). A pesar de todos estos estudios, la información sobre las localidades y preferencias de hábitat es precaria y se encuentra dispersa en multitud de colecciones de referencia, colectas personales y archivos gubernamentales, entre otros.

La mayor parte de los murciélagos recolectados en La Española se encuentran depositados en museos de Estados Unidos, destacándose las colecciones del Museo de Historia Natural James R. Slater y el Museo de Historia Natural de la Universidad de Kansas (Núñez-Novas y León, 2011). En la isla la única y más importante colección de referencia es la del Museo Nacional de Historia Natural "Profesor Eugenio de Jesús Marcano" (MNHNSD), iniciada por José A. Ottenwalder a principios de los 70 (Núñez-Novas y León, 2011), quien además publicó varios artículos sobre los murciélagos de la isla (Ottenwalder, 1978, 1979, 1981, 1995; Ottenwalder y Genoways, 1982). En dicha colección también aportaron especímenes diferentes naturalistas, como Nelson García Marcano, quien además ha realizado la mayor parte de los inventarios sobre murciélagos en el Ministerio de Medio Ambiente y Recursos Naturales de la República Dominicana (García-Marcano y Dominici, 2002a, b; García-Marcano, 2003; 2005a, b; 2006a, b; 2011; García-Marcano et al., 2011).

También, hay que destacar los aportes de Norma Fabián Calcagno, médico veterinario que citó por primera vez en la isla a la especie Tonatia silvicola (Lophostoma silvicolum); el virus de la rabia en murciélagos; el hongo patógeno Histoplasma capsulatum e identificó otras posibles enfermedades asociadas a los excrementos de los murciélagos (Gómez-Gonzáles y NevarezRivera, 1987; Figueroa-Espinosa y Vicente-Olaverria, 1990; Fabián-Calcagno, 2004, 2011).

Es imperativo crear instrumentos y programas para el conocimiento e investigación de los murciélagos. En este contexto, cabe destacar la importancia de las guías y claves de identificación como instrumentos imprescindibles para determinar rasgos comunes y diferencias entre las familias y entre especies. Una de las primeras claves de identificación de murciélagos para las Antillas Mayores fue elaborada por Ronald Herbert Pine (1980), en la que se establecían los caracteres diagnósticos de las 17 especies conocidas para La Española en ese momento. Posteriormente, se publicó la clave de identificación de quirópteros de las Antillas, que se convirtió en la clave de referencia para los murciélagos en el Caribe (Baker et al., 1984). Subsiguientemente, Rodríguez-Durán y Christenson (2012), publican un resumen sobre los 
murciélagos de varias islas en las Antillas, el mismo contiene generalidades sobre los murciélagos e información sobre la distribución, historia natural y descripción para cada una de las especies. Por último, Flanders et al. (2014), diseñan una clave ilustrada de campo, basada en datos obtenidos durante viajes de investigación a la isla, la información recogida resultó ser insuficiente, razón por lo que necesitaron recurrir a datos de Baker et al. (1984).

Hasta el 2017, en La Española habían registradas 18 especies de murciélagos, pero en un estudio llevado a cabo por Soto-Centeno et al. (2017) se encontró la presencia actual de dos especies: Pteronotus macleayii y Lasiurus cinereus, esta última reportada sólo para Haití. Por lo que se ha incrementado a 20 el número de especies reportadas para la isla, estas últimas no serán incluidas en esta guía.

\section{OBJETIVO}

-Elaborar una guía ilustrada de los murciélagos de La Española con la mayor representatividad de morfos.

\section{MATERIALES Y MÉTODOS}

Se visitaron distintas localidades a través de todo el territorio de República Dominicana durante los años 2008-2018, con el fin de obtener la mayor cantidad de datos que pudieran representar la variabilidad de morfos que presentan las especies y validarlos.

Las localidades visitadas fueron las siguientes: Cueva del agua, Cueva Honda de Julián, Cueva La Chepa, Cueva La Entrada, Cueva Los Patos, Cueva de Mara, Cueva Rancho La Guardia, Cueva Trunícolas y Cuevas del Pomier. Así como distintos abrigos rocosos y zonas boscosas en Baní, Barahona, Isla Catalina, María Trinidad Sánchez, Monte Plata, Pedernales, Samaná, San Cristóbal, Sánchez Ramírez y Santo Domingo, y zonas montañosas como el Hoyo de Pelempito y Sierra de Bahoruco.

Se utilizaron tres métodos de captura: una trampa de arpa de $1.83 \mathrm{~m}$ de ancho por $1.27 \mathrm{~m}$ de altura mínima y $2.29 \mathrm{~m}$ de altura máxima, red de mano o entomológica y redes de niebla de distintas longitudes según la localidad. Las especies se determinaron siguiendo a Silva-Taboada (1979) y Baker et al. (1984). Mientras que los nombres se estandarizaron siguiendo a NúñezNovas y León (2011). Para cada individuo se determinó: especie, sexo (Fig. 1) y madurez sexual (Fig. 2). Además, se registraron los datos morfométricos: longitud total (LT), longitud de la cola (LC), longitud del antebrazo (LA), longitud de la pata (LP), longitud de la oreja (LO), longitud del trago (LTr) y peso en gramos (gr), (Fig. 3). Se fotografió al menos un individuo de cada especie por localidad, en vistas lateral, escogiéndose una foto por especie para ser incluida en la guía; para aquellas especies que no pudieron ser capturadas se presentan fotos que fueron donadas.

Se examinaron las colecciones de murciélagos del Museo Nacional de Historia Natural "Prof. Eugenio de Jesús Marcano" (en seco y en húmedo), donde se revisaron los catálogos y etiquetas. Se validó la información de las medidas presentes en las etiquetas, volviendo a realizar las mediciones y dejando un margen de variación de $2 \mathrm{~mm}$; debido a que el tamaño de los especímenes preservados en alcohol tienden a ser ligeramente distinto al de animales vivos. Por último se incluyeron datos de la expedición llevada a cabo por Jon Flanders, Laurel Yohe, Stephen Rossiter y Liliana M. Dávalos en 2014. 

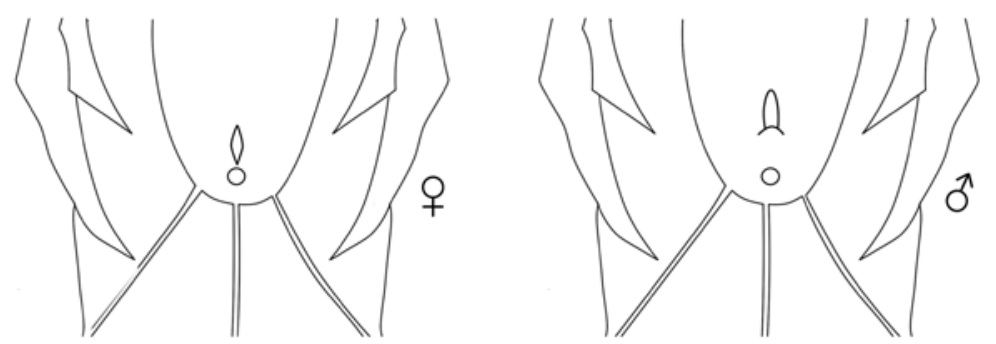

Figura 1. Ubicación de los genitales por sexo.
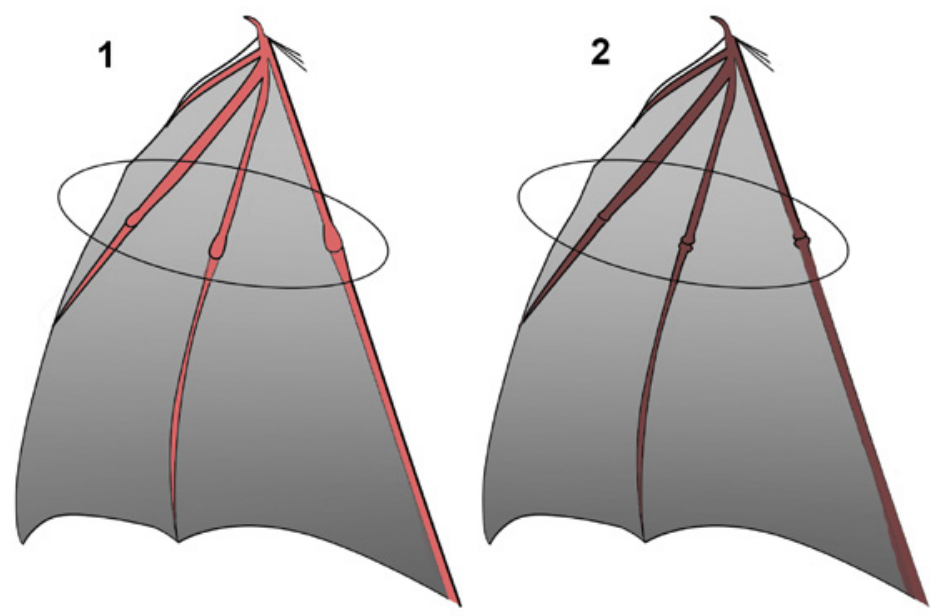

Figura 2. Grado de osificación de la epífisis. 1, juvenil; 2, adulto.

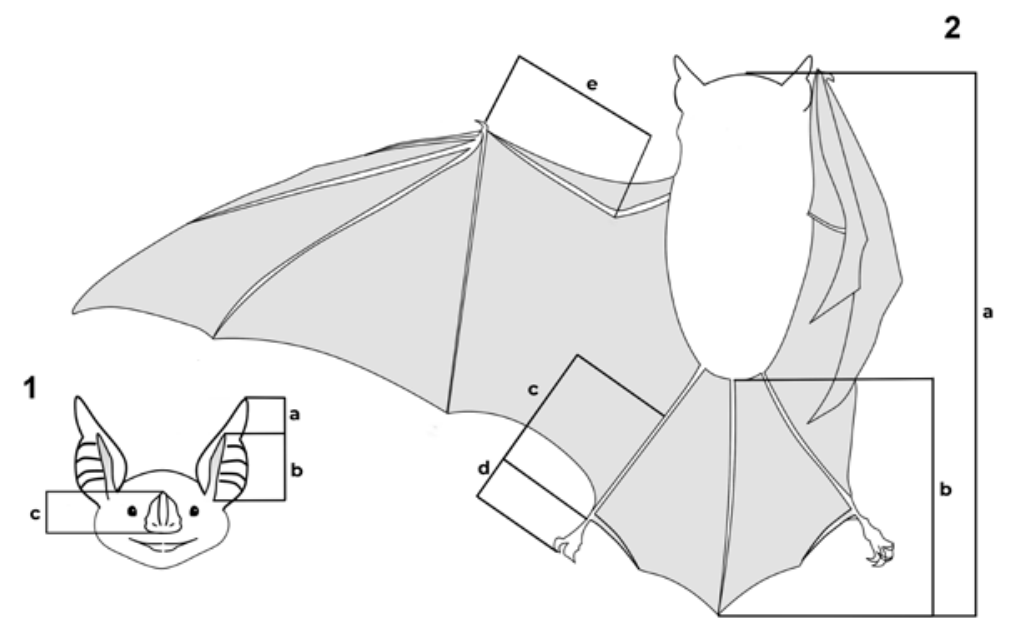

Figura 3. Medidas externas. 1. medidas de la cara: a, longitud de la oreja; b, longitud del trago; c, longitud de la hoja nasal. 2. medidas del cuerpo: a, longitud total; b, longitud de la cola; c, longitud desde la rodilla hasta la punta de los las uñas; d, longitud del tobillo a la punta de la las uñas; e, longitud del antebrazo. 
Toda la información obtenida se digitalizó en una base de datos elaborada en el programa Excel, de donde se extrajeron las longitudes de antebrazo, mínima y máxima por cada especie, para ser incluidas en la guía.

Los mapas de distribución de cada especie fueron confeccionados utilizando la base de datos elaborada por Núñez-Novas (2014), para los cuales se aplicó una malla de cuadrículas de $10 \mathrm{~km}^{2}$, donde cada cuadricula representa el área en la que ha coincidido una o más registros de colectas.

\section{RESULTADOS Y DISCUSIÓN}

Se obtuvieron datos de un total de 1072 individuos. Las especies Artibeus jamaicensis, Macrotus waterhousii y Molossus molossus, registraron el mayor número de ejemplares. Mientras que Chilonatalus microtus, Nyctinomops macrotis y Eptesicus fuscus presentaron el menor número de registros. La familia con el mayor número registros fue Phyllostomidae, esto era de esperarse ya que es el grupo con mayor riqueza de especies (7). Además, algunos de sus miembros son especies generalistas y con hábitos fitófagos. Por otra parte, Natalidae y Noctilionidae fueron las familias con el menor número de registros. En el caso de Natalidae, las dos especies que incluye esta familia son consideradas como raras y poco abundantes, y Noctilionidae solo posee una especie (Núñez-Novas y León, 2011; Núñez-Novas et al., 2016). Molossidae resultó ser la familia de la que menos individuos pudieron ser capturados. Debido a esto, la mayor parte de los datos ofrecidos sobre esta familia provienen de ejemplares presentes en la colección.

El proceso con los especímenes del museo presentó algunos inconvenientes, tales como: imposibilidad de medir los especímenes preservados en seco y comprobación de los datos presentes, ya que correspondían a ejemplares no presentes en la actualidad en el museo o liberados en el campo. Los rangos de algunas medidas presentaron intervalos muy amplios de variaciones. Pudiendo esto deberse a que se tomaron datos de especímenes juveniles, sub-adultos u otras situaciones no contempladas. Aun así, se ha decidido incluir esta información, ya que se considera fiable debido a que fueron tomadas por investigadores calificados entre los años 80-90 (Tabla I). La medida que menos variaciones presentó, si se compara con datos reportados en la literatura, fue la longitud del antebrazo (LA). Por esta razón se pueden considerar las más precisas (Tabla I).

A continuación, se presentan dos claves dicotómicas, una para las familias y otra para las especies, ambas acompañadas de imágenes como soporte: para las familias, cinco esquemas generales de las colas; para las especies, fotografías del rostro. En los esquemas de las colas se ha excluido la familia Phyllostomidae debido a que la presencia o ausencia de cola puede variar según las especies. 


\section{Clave para la identificación de las familias de murciélagos de la Española}

1A. Hoja nasal presente....... Phyllostomidae

1B. Hoja nasal ausente.

2A. Cola gruesa, extendida ampliamente más allá del uropatagio (Fig. 4) ...... Molossidae

2B. Cola delgada, sin extenderse más allá del borde del uropatagio y en caso de hacerlo no más de $5 \mathrm{~mm}$ 3

3A. Cola extendiéndose hasta el borde del uropatagio o sobresaliendo levemente...... 4

3B. Cola sin extenderse hasta el borde del uropatagio......... 5

4A. Orejas cubriendo parcialmente los ojos, cola extendiéndose hasta el borde del uropatagio (Fig. 4)... Natalidae

4B. Orejas sin cubrir los ojos; cola se extiende al borde posterior del uropatagio o sobresaliendo levemente y termina en forma de "V" (Fig. 4) .......... Vespertilionidae

5A. Labio superior normal e inferior con repliegues; antebrazo menor de 80mm (Fig. 4) ...... Mormoopidae

5B. Labio superior leporino o hundimiento del labio superior, labio inferior normal y antebrazo mayor de $80 \mathrm{~mm}$. Noctilionidae (Fig. 5); Noctilio leporinus (Linnaeus, 1758)

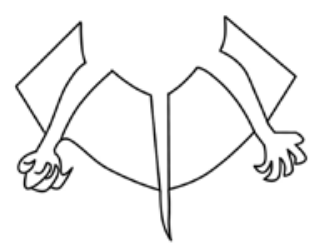

Molossidae

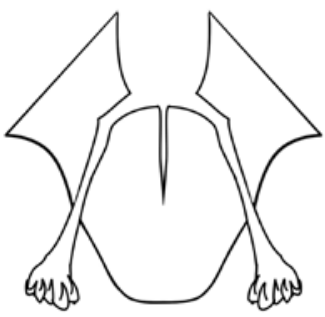

Mormoopidae

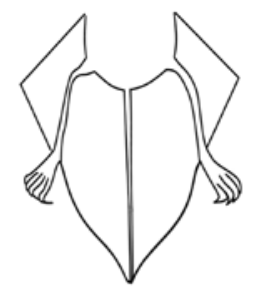

Natalidae

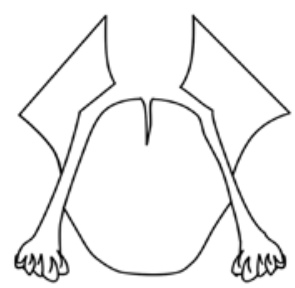

Noctilionidae

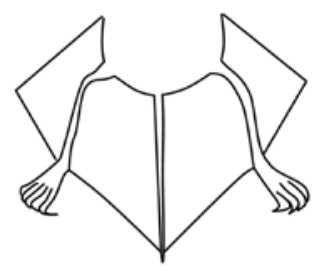

Vespertilionidae 


\section{Clave para la identificación de las especies de murciélagos de La Española}

Familia Phyllostomidae

1A. Cola ausente o no visible externamente.

1B. Cola presente y visible externamente... 4

2A. Hoja nasal rudimentaria con presencia de repliegues dérmicos alrededor de la nariz; hocico chato y alargado; LA 52-63 mm; (Fig. 6) .Brachyphylla pumila Miller, 1918

2B. Hoja nasal prominente y hocico corto . 3

3A. Antebrazo mayor a $47 \mathrm{~mm}$; líneas grises en la cabeza (pudiendo estar ausentes); LA 46-62 mm; (Fig. 7) Artibeus jamaicensis Leach, 1821

3B. Antebrazo menor a $47 \mathrm{~mm}$ y manchas blancas en los hombros; LA 38-45 mm; (Fig. 8)..... Phyllops falcatus (Gray, 1839)

4A. Orejas muy grandes, mayores a $21 \mathrm{~mm}$; LA 38-57 mm; (Fig. 9)

Macrotus waterhousii Gray, 1843

4B. Orejas pequeñas, menores a $20 \mathrm{~mm}$ .5

5A. Espolón mayor de 3 mm; hocico fino; LA 37-42 mm; (Fig. 10)

Monophyllus redmani Leach, 1821

5B. Espolón menor de $3 \mathrm{~mm}$ o ausente; hocico alargado..... 6

6A. Espolón presente; tibia más corta que la mitad de la longitud del antebrazo; transición del cráneo al hocico pronunciada; hoja nasal menor de $2 \mathrm{~mm}$; ausencia de verruga en el nacimiento de la oreja; LA 42-51 mm; (Fig. 11)...... Erophylla bombifrons (Miller, 1899)

6B. Espolón ausente; tibia tan larga o más que la mitad de la longitud del antebrazo; transición del cráneo al hocico lineal y suave; hoja nasal rudimentaria o inexistente; presencia de verruga cerca del nacimiento de las orejas; LA $42-51 \mathrm{~mm}$; (Fig. 12)........Phyllonycteris poeyi Gundlach, 1861

Familia Molossidae

1A. Longitud del antebrazo mayor de 54 mm; LA 55-61 mm; (Fig. 13)............. Nyctinomops macrotis (Gray, 1840)

1B. Longitud del antebrazo menor de $54 \mathrm{~mm}$. 2

2A. Orejas grandes, sin unirse y sobrepasando moderadamente el hocico; LA 38-43 mm; (Fig. 14)....... Tadarida brasiliensis (I. Geoffroy, 1824)

2B. Orejas pequeñas, unidas en la línea media del hocico y sin sobrepasarlo; LA 37-40 mm; (Fig. 15). Molossus molossus (Pallas, 1766) 
Familia Mormoopidae

1A. Orejas unidas por un pliegue con algunas excrecencias en el borde superior de la nariz, casi rodeando todo el ojo; LA 41-50 mm; (Fig. 16)...... Mormoops blainvillei Leach, 1821

1B. Orejas separadas y alargadas con algunas excrecencias sobre los nostrilos.......... 2

2A. Antebrazo mayor a 47 mm; LA 39-52 mm; (Fig. 17).......Pteronotus parnellii (Gray, 1843) 2B. Antebrazo menor a $41 \mathrm{~mm}$; LA $34-40 \mathrm{~mm}$; (Fig. 18)..... .Pteronotus quadridens (Gundlach, 1840)

Familia Natalidae

1A. Antebrazo mayor de 42 mm; membrana del ala unida al tobillo; LA 40-49 mm; (Fig. 19) Natalus major Miller, 1902

1B. Antebrazo menor de $36 \mathrm{~mm}$; membrana del ala unida por encima del tobillo; LA 32-42 mm; (Fig. 20) Chilonatalus micropus (Dobson, 1880)

Familia Vespertilionidae

1A. Antebrazo mayor de 42 mm; ausencia de manchas; LA 44-51 mm; (Fig. 21) .Eptesicus fuscus (Beauvois, 1796)

1B. Antebrazo menor de $42 \mathrm{~mm}$; manchas blancas en los hombros; LA $37-43 \mathrm{~mm}$; (Fig. 22) Lasiurus minor Miller, 1931

\section{Algunas anotaciones sobre las familias y especies}

Se enumeran algunas observaciones de las familias y especies, compiladas durante los últimos 10 años de recolecta, en zonas abiertas, bosques, cuevas, abrigos rocosos y lugares urbanos. Se han incluido datos de hora de éxodo y época reproductiva de Núñez-Novas et al. (2014).

\section{Noctilionidae}
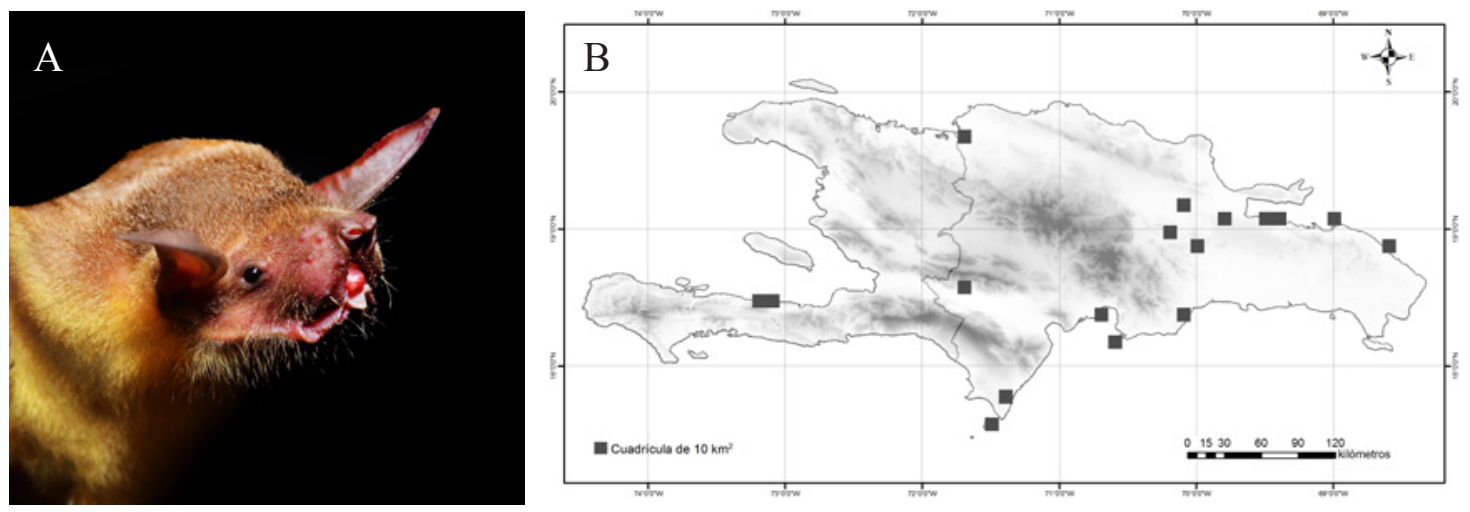

Figura 5. Noctilio leporinus. A, vista lateral, CE. Calderón-Dávila. B, mapa de distribución. 
Noctilio leporinus. Nativa. Es una especie piscívora, aunque puede alimentarse de insectos. Generalista en el uso de refugios, pudiendo utilizar cuevas o arboles como refugio diurno. Es el murciélago más grande de la isla. La presencia de esta especie en cueva pudiera ser indicador de la existencia de algún cuerpo de agua cercano o en su interior. Ha sido capturada ingresando en una cueva inundada, pudiendo utilizar la misma como refugio nocturno o lugar de alimentación. Fue capturada en noches de luna llena, por lo que la fobia lunar pudiera no presentarse en ella. Se ha encontrado hembras preñadas en los meses de marzo y abril, y lactando en septiembre. Tiene a menudo colores brillantes que varían entre amarillo-rojizo a grisáceo-marrón.

\section{Phyllostomidae}

La familia Phyllostomidae es la más diversa de La Española. Las especies que la componen han explotado al máximo el ambiente que les rodea ya que, incluyen especies insectívoras, frugívoras y polinívoras. En su mayoría habitan en recintos cavernarios y cuevas calientes, el resto pueden utilizar una amplia gama de hábitats de refugio: árboles y casas, entre otros.
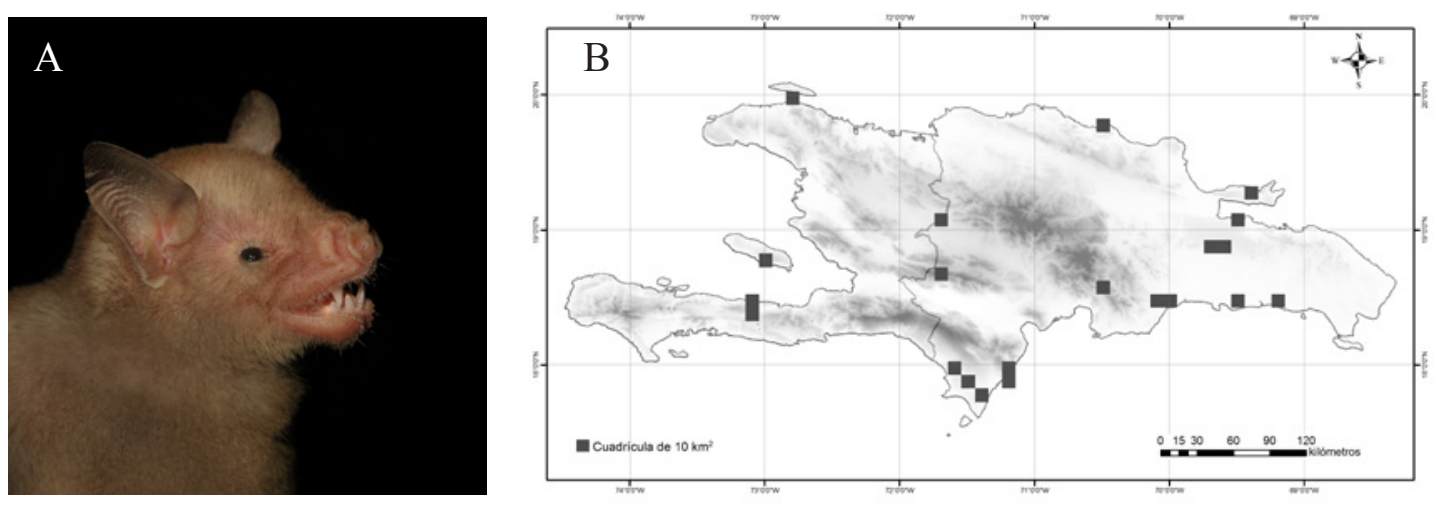

Figura 6. Brachyphylla pumila. A, vista lateral, CM.S. Núñez-Novas. B, mapa de distribución.

Brachyphylla pumila. Nativa. Es una especie frugívora, puede consumir insectos. Es obligatoria de cuevas. Estuvo presente en cuevas con una amplia cobertura boscosa y cerca de fuentes de agua. Se encontró compartiendo el hábitat con $P$. poeyi y $P$. quadridens, especies indicadoras de cuevas calientes. Los ejemplares de esta especie, al ser capturados, no dejan de moverse y luchar para liberarse, emiten un chillido muy agudo y molesto. Se puede encontrar en forma solicitaría o formando colonias de varios cientos de individuos. Fue capturada en la cueva Los Patos, donde se presenta como la especie más común, existiendo una colina con cientos de individuos. En dicha cueva se han contabilizado en una noche más 90 individuos en menos de 4 horas de muestreo. Se ha encontrado hembras preñadas en febrero, mientras que en agosto se presentaron preñadas, lactando o paridas. En julio y septiembre se encontraron sólo lactando. Es una especie nocturna, la mayor parte de los individuos suelen salir de las cuevas entre 19:00-20:00 h. Por su alimentación frugívora, es común que tenga flatulencias pestilentes. Presenta una coloración grisácea que pudiera ser tenue en juveniles, también una cola rudimentaria, aunque algunos autores no la consideran como tal. 

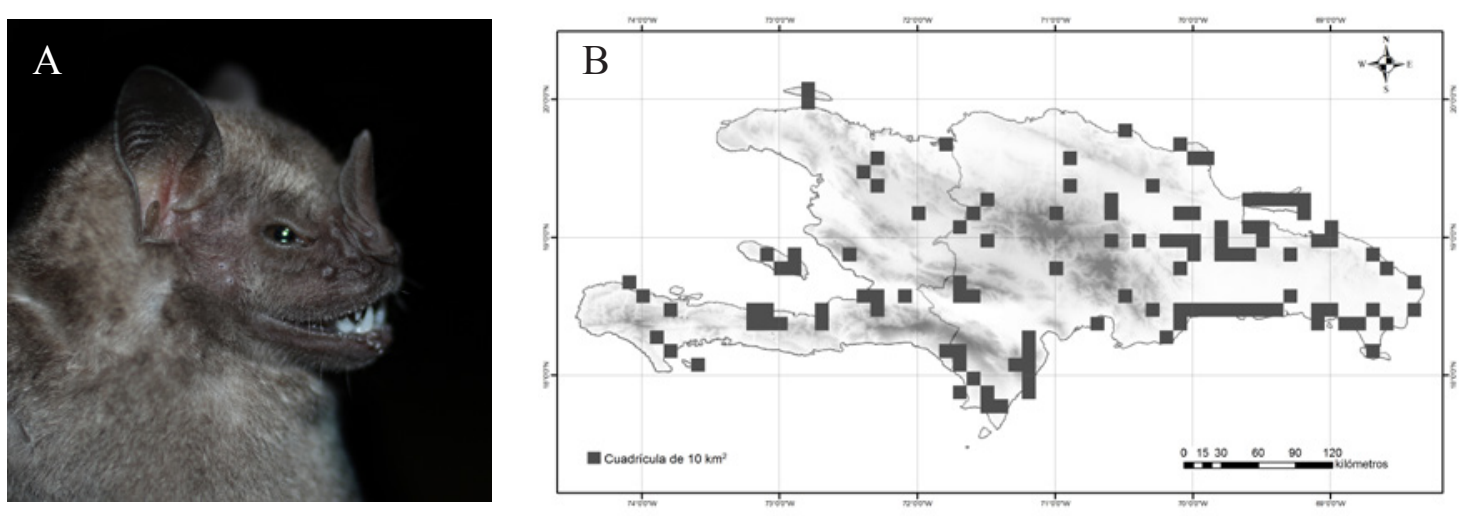

Figura 7. Artibeus jamaicensis. A, vista lateral, CM.S. Núñez-Novas. B, mapa de distribución.

Artibeus jamaicensis. Nativa. Es una especie frugívora pudiendo consumir, néctar y polen. Es la más común y abundante en áreas boscosas y urbanas, pudiendo utilizar una amplia gama de hábitats de refugio: cuevas, árboles, casas, entre otros. Se puede encontrar en forma solicitaría o formando colonias de varias decenas de individuos. En las cuevas suele ubicarse en la entrada y es reconocible por la presencia de plántulas en su suelo, siendo la almendra y algunas palmas las más comunes. Es una especie corpulenta. Las hembras suelen ser menos agresivas que los machos, aunque ambos al ser manipulados suelen estar tranquilos. En colonias con muchos individuos algunos machos presentan los testículos muy desarrollados, posiblemente debido a la competencia espermática. Muestra dos picos reproductivos al año: junio-julio y diciembrefebrero, sin embargo, se han observado algunas hembras preñadas, paridas o lactando durante los meses de marzo-abril, agosto-septiembre y solo lactando en el mes de mayo. Es una especie crepuscular-nocturna, saliendo de las cuevas desde las 18:00 h, su pico de salida es alrededor de las 19:00-20:00 h. Presenta dos líneas claras sobre la cabeza que se utilizan como carácter diagnóstico, aunque algunos individuos no las presentaban. Presentan una coloración grisácea oscura.
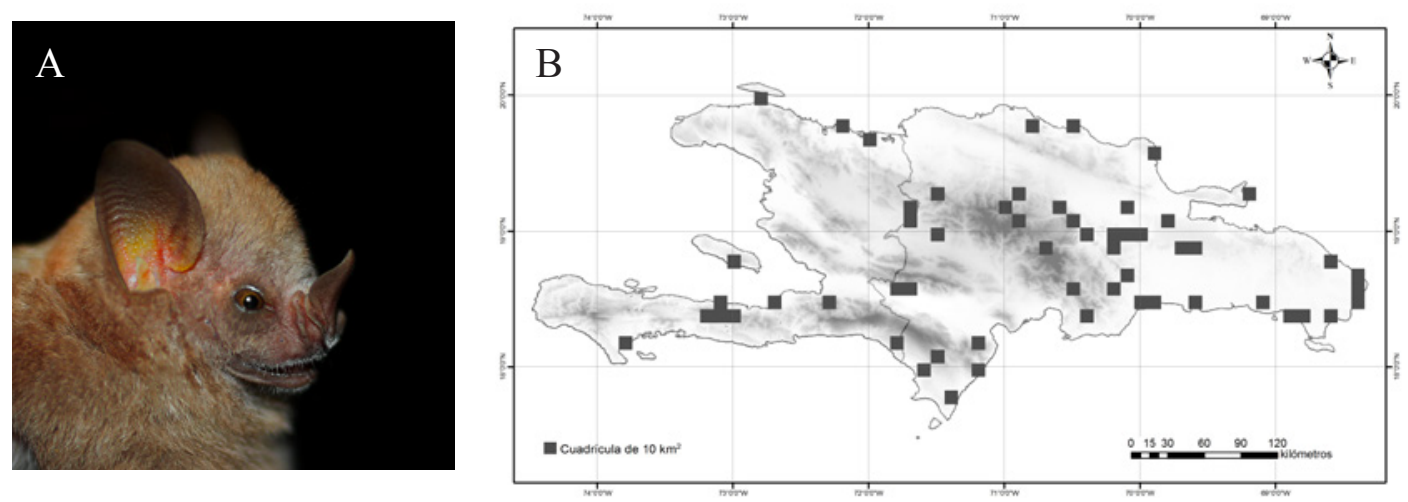

Figura 8. Phyllops falcatus. A, vista lateral, CM.S. Núñez-Novas. B, mapa de distribución.

Phyllops falcatus. Nativa. Especie frugívora y arborícola, aunque existen registros de colecta dentro de cuevas. En muestreos realizados en zonas boscosas y cercanas a fuentes de agua suele ser una de las especies más comunes. Forma grupos de pocos individuos. Se han visto menos de siete individuos perchados en ramas. Se ha atrapado en redes desde las 21:00 h. Esta especie posee dos manchas blancas muy visibles en los hombros. 

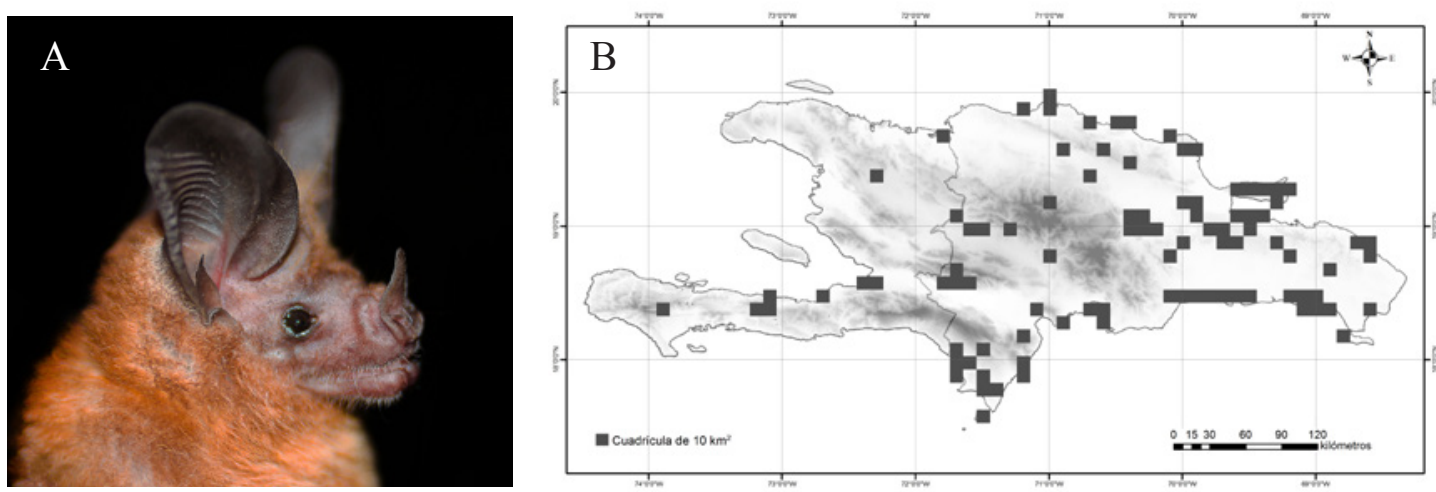

Figura 9. Macrotus waterhousii. A, vista lateral, CM.S. Núñez-Novas. B, mapa de distribución.

Macrotus waterhousii. Nativa. Especie insectívora. Es la más común en cuevas y abrigos rocosos. Estuvo presente en la mayor parte de los abrigos rocosos visitados. En algunos casos fue la única especie presente en este tipo de formación. Se puede hallar en forma solitaria o formando colonias de decenas a cientos de individuos. Comúnmente, se encuentra en la entrada de las cuevas. La presencia de alas de lepidóptera en el suelo de la cueva, puede ser útil para detectar esta especie. Se ha encontrado en cuevas inundadas. Suele tener una gran cantidad de garrapatas y moscas sobre su cuerpo. Algunos individuos presentaron algo similar a la escabiosis detrás de las oreja. Las hembras se han presentado preñadas en los meses de febrero, abril, mayo y septiembre. En julio y agosto se mostraron lactantes. Es una de las especies que más temprano salen de las cuevas: entre 18:00 y 19:00 h, debido a esto es considera como vespertinacrepuscular. Presentan una coloración grisácea.
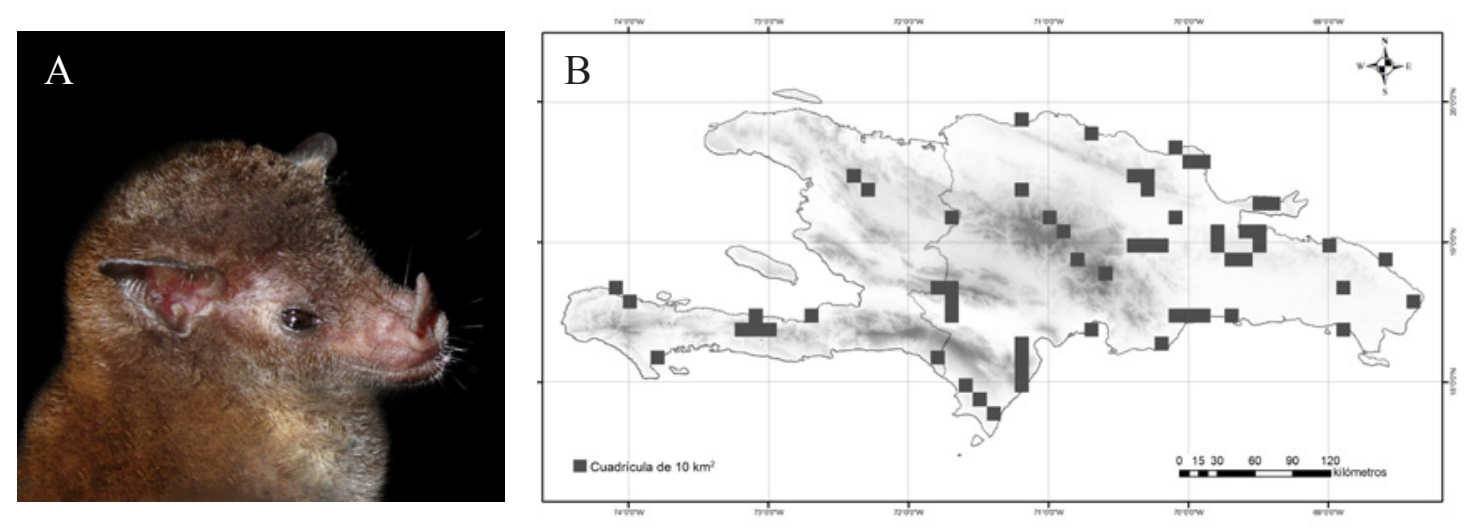

Figura 10. Monophyllus redmani. A, vista lateral, CSoto-Centeno. B, mapa de distribución.

Monophyllus redmani. Nativa. Especie nectarívora, pudiendo llegar a ser generalista. Obligatoria de cuevas. Tiene preferencia por zonas boscosas y desérticas. Se puede hallar formando colonias de varias decenas individuos. Se ubica en la parte media o profunda de la cueva. Pueden ocupar de forma temporal las cuevas, relacionándose esto a la segregación sexual, disponibilidad de alimentos o perturbaciones antropogenicas. En muestreos realizados en el bosque seco de la zona sur, fue capturada alimentándose de agave. Se han encontrado hembras grávidas en los meses de febrero, marzo, septiembre y diciembre. Esta especie puede empezar a salir desde las primeras horas de éxodo, aunque la mayor parte se concentra entre las 19:00-20:00 h, por lo que es considerada nocturna. Presentan una coloración negruzca. 

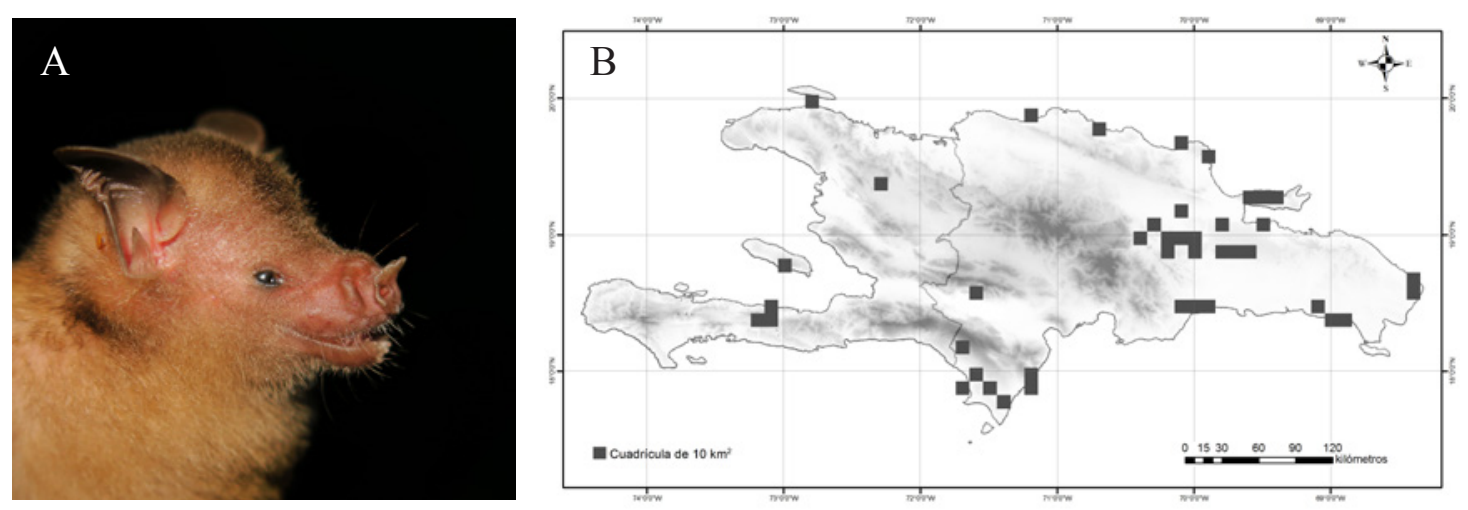

Figura 11. Erophylla bombifrons. A, vista lateral, CM.S. Núñez-Novas. B, mapa de distribución.

Erophylla bombifrons. Nativa. Especie generalista. Es obligatoria de cuevas. Se puede encontrar formando colonias de varias decenas de individuos. Suele ubicarse en la parte media o profunda. Se podría considerar una de las especies más difíciles de manipular ya que al igual que B. pumilia, al ser capturada no para de moverse y luchar para liberarse. Realiza intentos repetidos de atacar a quien la está manipulando. Esta situación lleva algunos individuos a episodios de frenesís que los lleva a autoatacarse y continúan haciéndolo aún después de ser liberados. Posee un chillido muy agudo y molesto. Se han hallado hembras grávidas en los meses de febrero y abril, en agosto y septiembre preñadas, lactando o paridas. Es una especie nocturna, suele salir de las cuevas desde las 19:00 $\mathrm{h}$ aunque la mayor parte sale entre 20:00-21:00 h. Posee una coloración variable según la edad del individuo y condiciones dentro de las cuevas. Que van desde amarillo muy intenso en juveniles hasta un marrón tenue en adultos.
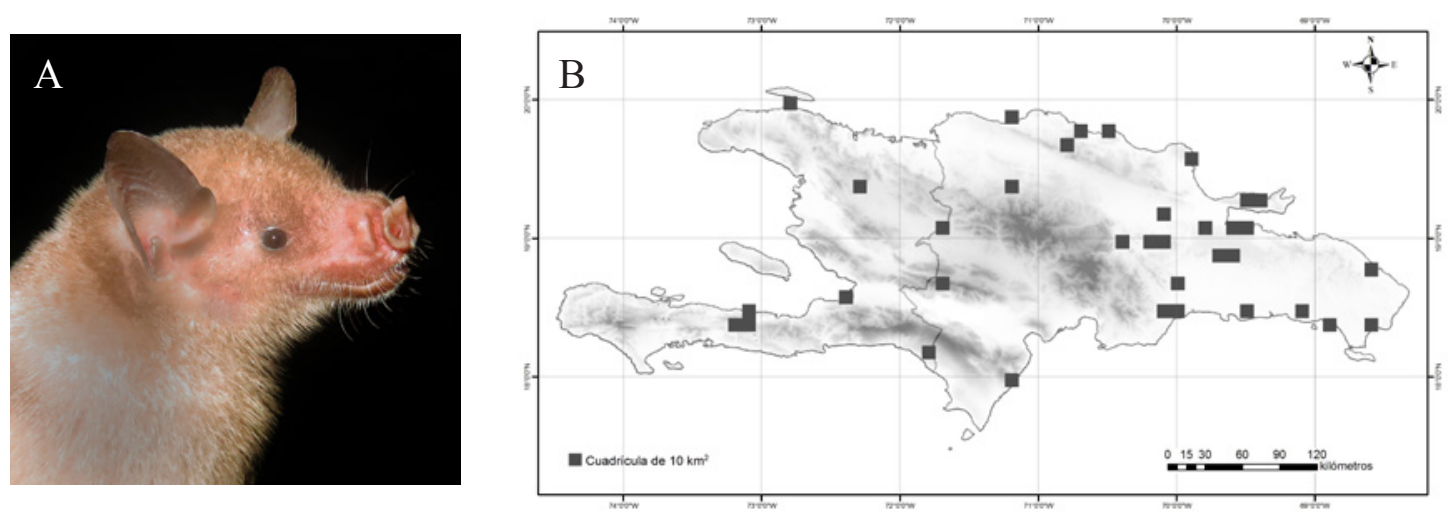

Figura 12. Phyllonycteris poeyi. A, vista lateral, CM.S. Núñez-Novas. B, mapa de distribución.

Phyllonycteris poeyi. Nativa. Especie generalista y obligatoria de cuevas. Indicadora de cuevas calientes. Forma colonias de decenas a miles de individuos como es el caso del complejo de Cuevas del Pomier, con una población de miles de individuos. Puede compartir el refugio con $E$. bombifrons, lo que hace que sean fáciles de confundir, si no se tienen en cuenta los caracteres diagnósticos que las diferencia. También pudiera ser confundida con juveniles de B. pumila, que pudieran tener una coloración amarillenta típica de $P$. poeyi. Se han encontrado hembras preñadas en los meses de febrero, marzo y diciembre. Es una especie nocturna que suele salir de entre las 19:00-20:00 h. Posee una coloración amarillenta que en algunos individuos tiende a crema. 


\section{Molossidae}
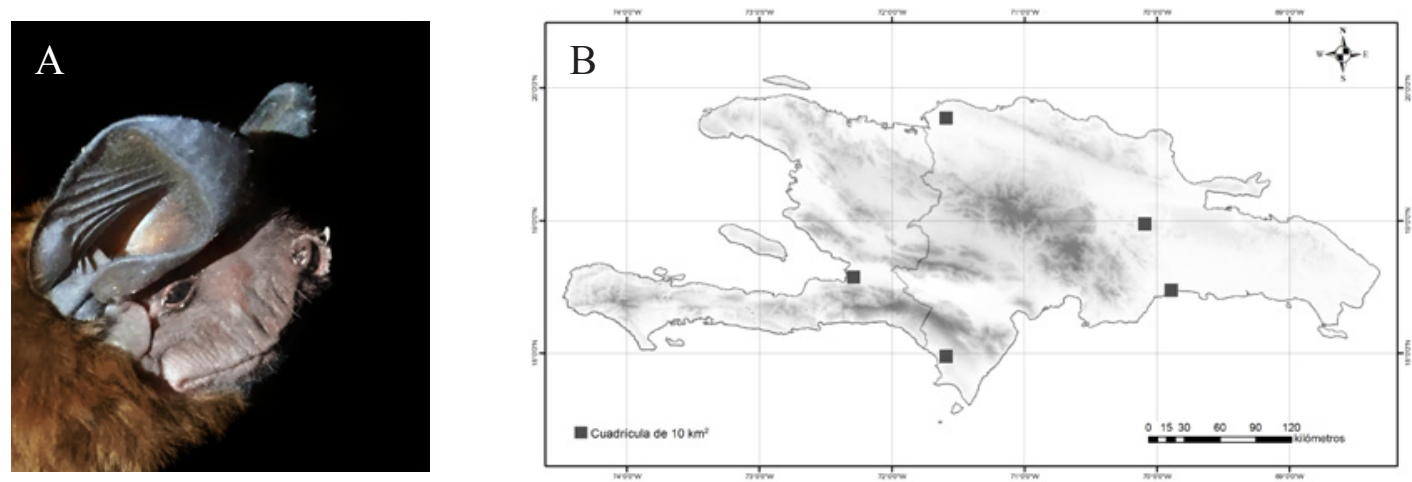

Figura 13. Nyctinomops macrotis. A, vista lateral, (C) R. Medellin. B, mapa de distribución.
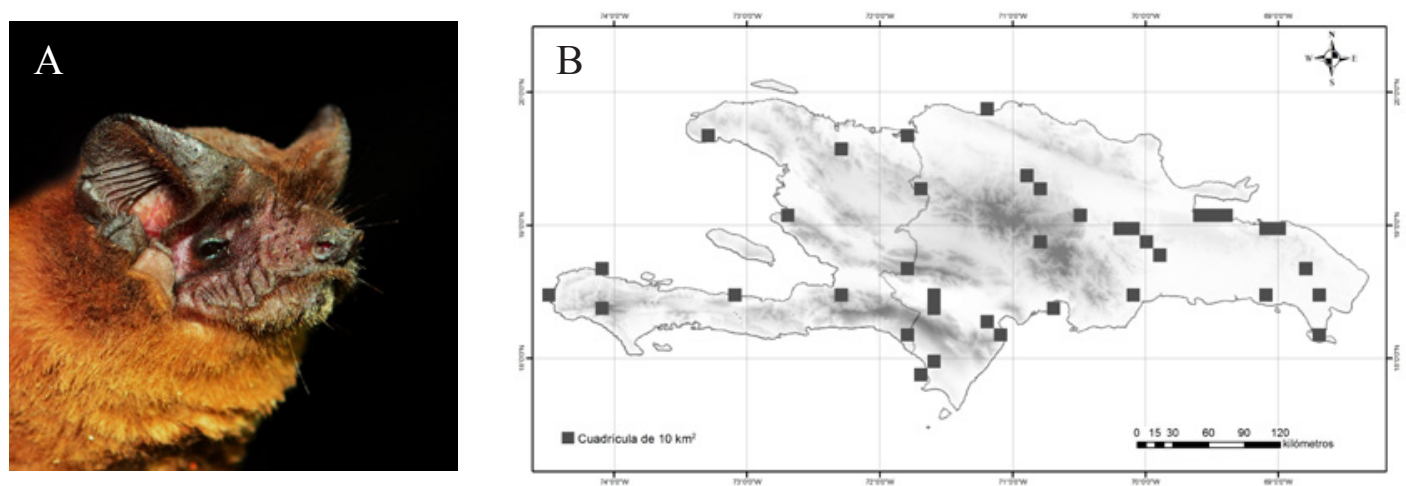

Figura 14. Tadarida brasiliensis. A, vista lateral, CE. Calderón-Dávila. B, mapa de distribución.
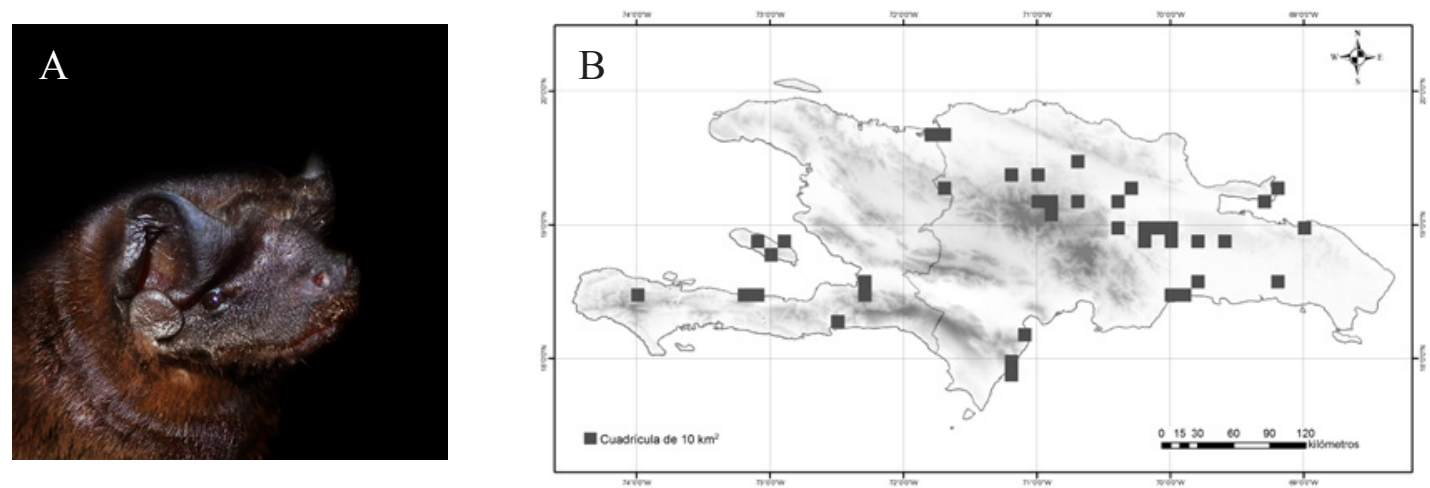

Figura 15. Molossus molossus. A, vista lateral, CE. Calderón-Dávila. B, mapa de distribución.

Esta familia era común en zonas urbanas durante los años 80-90. Posee preferencias por las construcciones antrópicas, probablemente, debido a que le sirven de refugio y sitio de alimentación, ya que las luces atraen algunos grupos de insectos. En las cuevas visitadas no se encontraron individuos de esta familia, a pesar de que se buscó en algunas donde había sido reportada, como La Chepa y Trunicolás. Sólo fue posible capturar algunos individuos de Molossus molossus, en una casa abandonada y en zonas boscosas. Tadarida brasiliensis fue capturada en zonas boscosas. La especie Nyctinomops macrotis no ha sido capturada desde 1986, motivo por el cual se encuentra en la Lista Roja Nacional. 


\section{Mormoopidae}

Los murciélagos de esta familia son de tamaño medio a pequeño. Poseen una boca en forma de embudo, en la que tienen una franja de pelos (por esto el nombre de bigotudos). Las tres especies presentes en La Española son insectívoras. La presencia de esta familia en cueva es indicadora de cierta estabilidad microclimática, ya que en su mayoría habitan en recintos cavernarios húmedos y abrigados. Estos se relaciona en mayor o menor grado con cuevas calientes. Son especies gregarias que pueden formar colonias de miles de individuos. En las cuevas donde están presentes todos los miembros de la familia, estos suelen ser los más abundantes. Representando más del 50\% del total de individuos capturados.
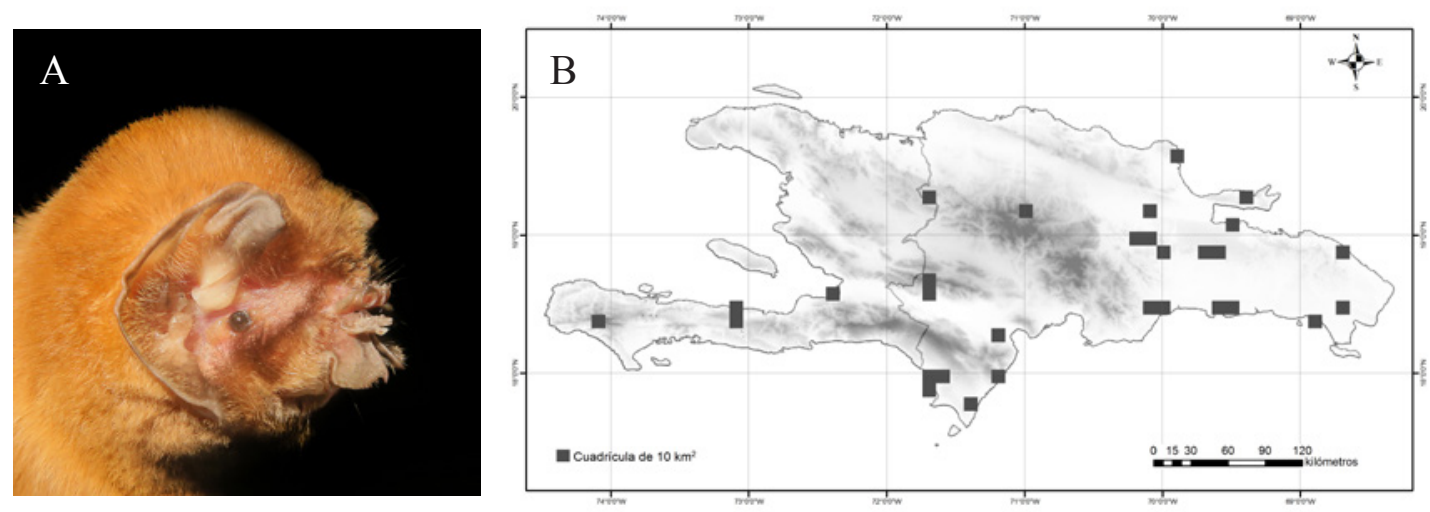

Figura 16. Mormoops blainvillei. A, vista lateral, CM.S. Núñez-Novas. B, mapa de distribución.

Mormoops blainvillei. Nativa. Especie insectívora y obligatoria de cuevas. Se puede encontrar formando colonias de decenas a cientos de individuos. Suele ubicarse en la parte media o profunda, de la cueva; aunque se han encontrado individuos cercanos a la entrada. Entre estos algunos muertos que seguían colgados del techo. Al igual que $M$. redmani, puede ocupar las cuevas temporalmente. Es una especie nocturna, aunque algunos individuos pueden salir de las cuevas a las primeras horas de éxodo 18:00 h. Sin embargo, la mayor parte suele salir de 21:00-22:00 h. Presentan una coloración que va desde rojo intenso en juveniles hasta rojo pálido en adultos.
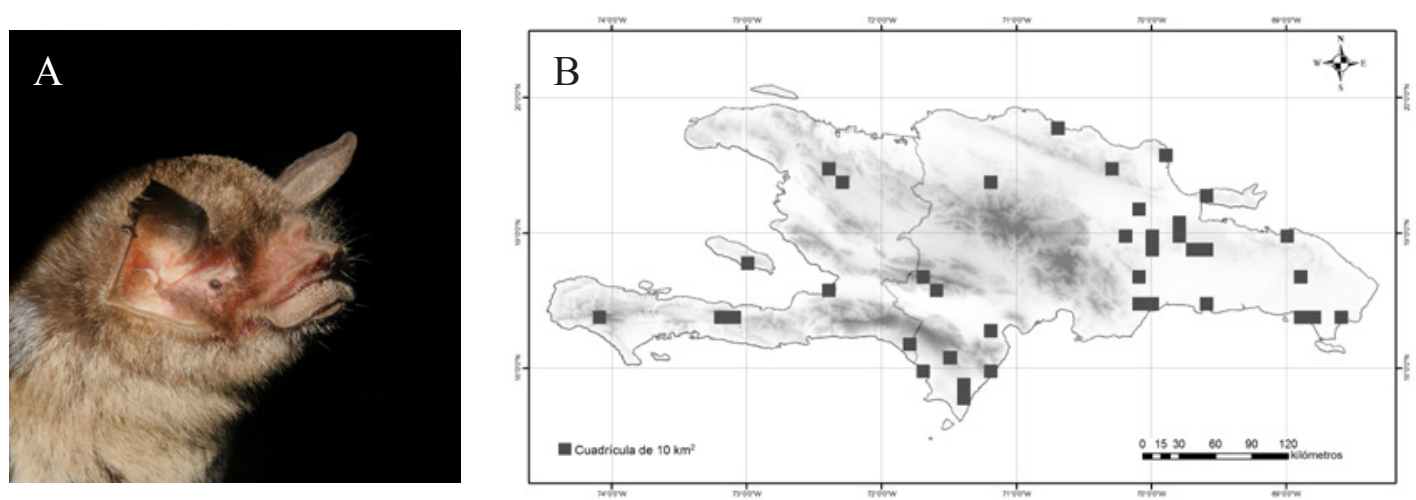

Figura 17. Pteronotus parnellii. A, vista lateral, CM.S. Núñez-Novas. B, mapa de distribución. 
Pteronotus parnellii. Nativa. Especie insectívora y obligatoria de cuevas. Especie común en cuevas y zonas boscosas. Forman colonias de decenas a cientos de individuos. Suele ubicarse en la parte media o profunda de la cuevas. Se ha encontrado compartiendo refugio con todas las especies que habitan en las cuevas. Al igual que $M$. redmani, puede ocupar de forma temporal las cuevas. Se han encontrado hembras grávidas en el mes de marzo y preñadas, lactando o paridas en septiembre. Al igual que $M$. waterhousii, es una de las primeras en empezar a salir de las cuevas, iniciando el éxodo a 18:00 h, aunque la mayor parte se concentra 19:00-20:00 h, por lo que es considerada noctura. Se han encontrado cuevas donde el éxodo puede durar varias horas como el caso de la Cueva Honda de Julián, donde la cantidad de murciélagos que salen se mantiene casi constante por más de 4 horas. Se han capturado más de 90 ejemplares en este lapso de tiempo. Presentan una coloración marrón oscura. Los individuos juveniles pueden ser ligeramente confundidos con $P$. quadridens, pero las medidas del antebrazo permitirían despejar la duda.
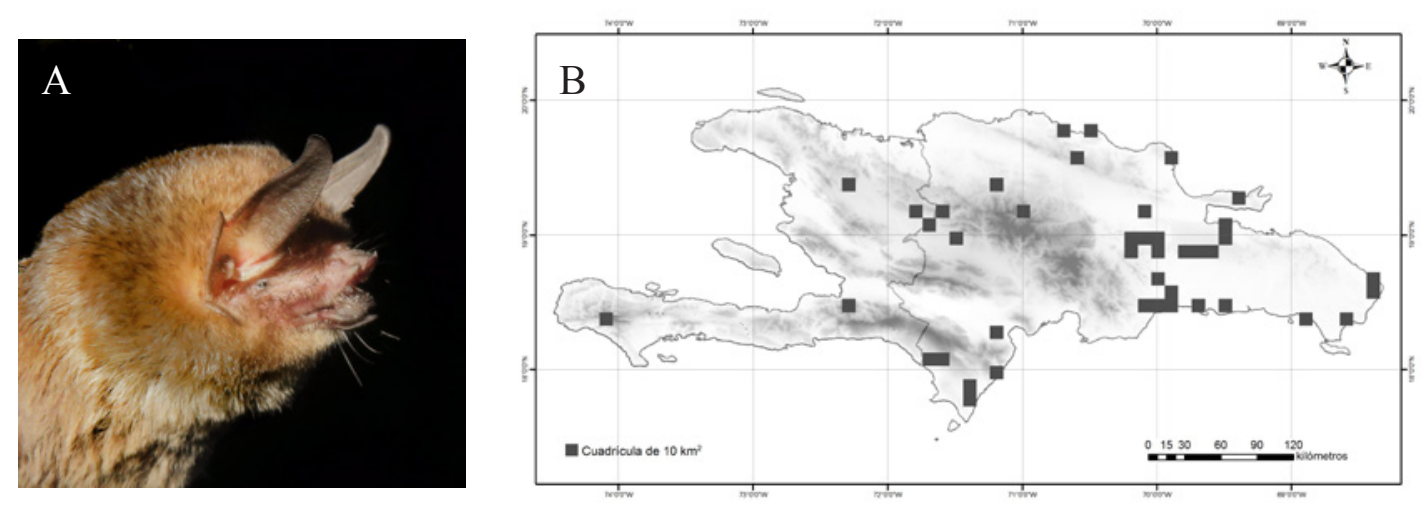

Figura 18. Pteronotus quadridens. A, vista lateral, CM.S. Núñez-Novas. B, mapa de distribución.

Pteronotus quadridens. Nativa. Especie insectívora y obligatoria de cuevas, también es indicadora de cuevas calientes. Puede formar colonias de decenas hasta cientos de individuos, se ubica en las zonas profundas de las cuevas. Suele compartir refugio con otros mormópidos. Se han encontrado hembras grávidas en entre los meses de marzo y mayo. También, en septiembre se han encontrado preñadas, lactando o paridas. Es una especie nocturna, aunque algunos individuos pueden salir de las cuevas a las primeras horas de éxodo, la mayor parte suele salir de 21:00-22:00 h, al igual que en P. parnellii su éxodo puede durar horas. Presentan una coloración marrón oscuro. Sus huesos son muy frágiles y se rompen con facilidad en especial el antebrazo, por lo que es vital tener mucho cuidado en su manipulación; algunos individuos al ser capturados empiezan a hiperventilar y pueden llegar a morir.

\section{Natalidae}

Sus grupos sociales son relativamente pequeños y se alimentan de insectos cazados al vuelo. Tiene presencia del órgano natalido (engrosamiento del hocico). Al igual que los mormópidos, prefieren cuevas abrigadas, húmedas y con fuentes de agua cercanas. 

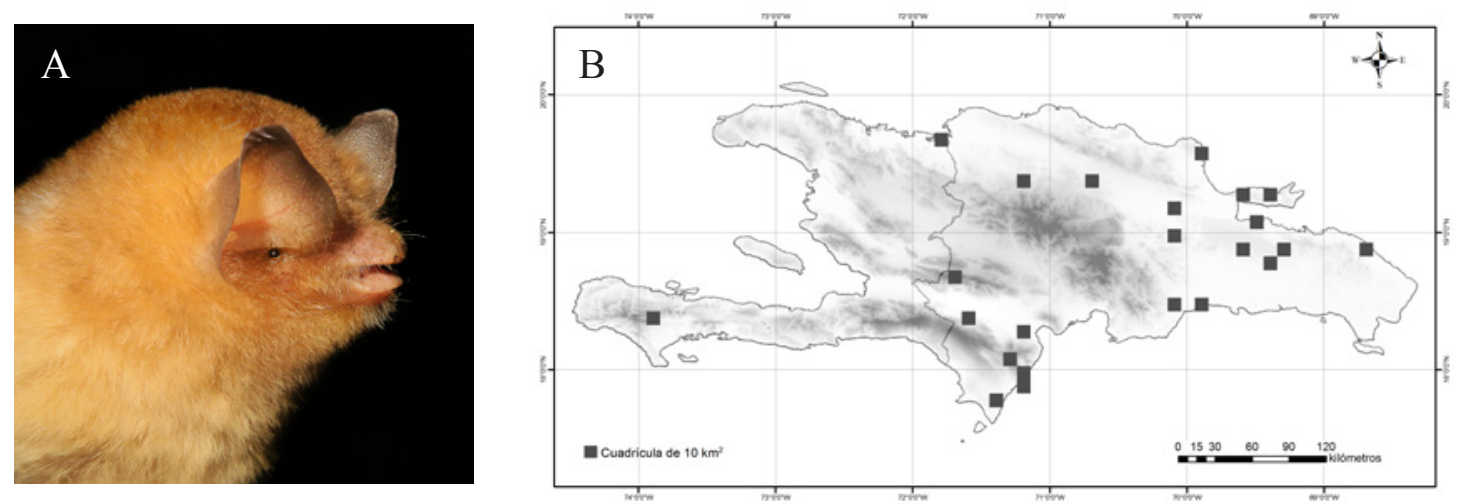

Figura 19. Natalus major. A, vista lateral, CM.S. Núñez-Novas. B, mapa de distribución.

Natalus major. Endémica. Especie insectívora y obligatoria de cuevas. Esta especie se ha asociado a cuevas inundadas o cuevas cercanas a fuentes de agua. Es una especie considerada como rara por lo que es poco abundante en los muestreos así como en las colecciones científicas. Forma colonias pequeñas pudiendo llegar a varias docenas. Fue la especie más abundante en una de las cuevas muestreadas en la región Sur. La colonia registrada debía tener más de 100 individuos, algo poco común en esta especie. Dicha cueva no parecía estar inundada, aunque a menos de $20 \mathrm{~m}$ se encontraba un riachuelo. Especie nocturna, saliendo desde las 19:00 h el mayor éxodo ronda las 21:00 h. Presentan una coloración grisácea clara con algunas tonalidades amarillentas. Es fácil de reconocer por tener las orejas puntiagudas y los dientes finos, los cuales se asemejan a pequeños alfileres. Los individuos juveniles pueden ser ligeramente confundidos con C. micropus, esta duda podría ser despejada midiendo el antebrazo.
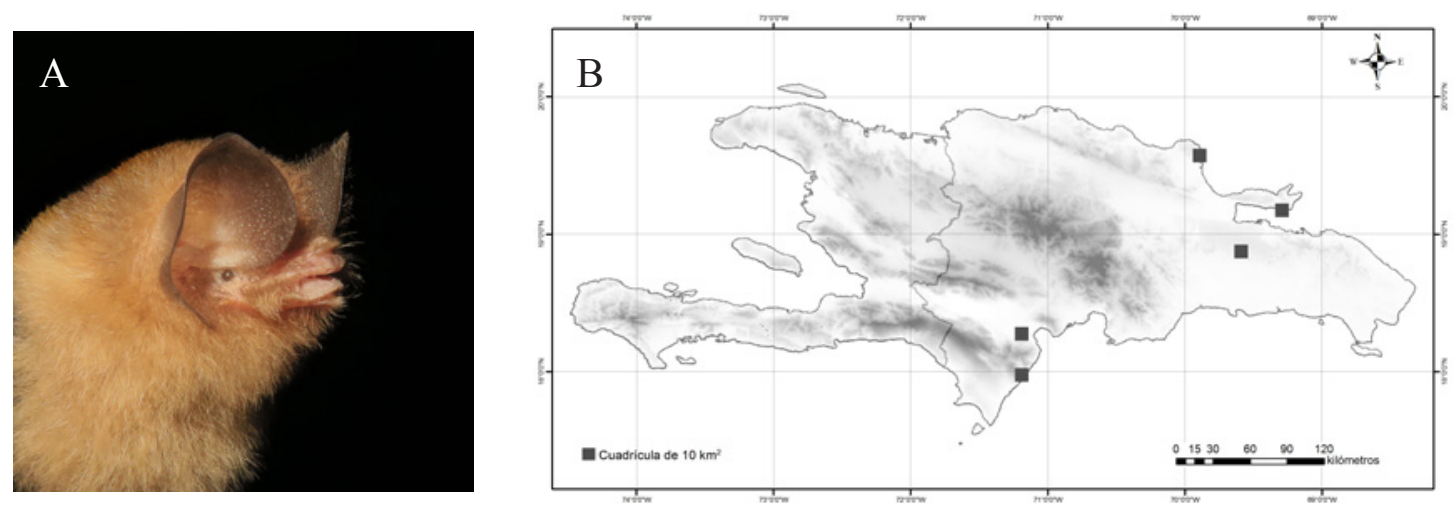

Figura 20. Chilonatalus micropus. A, vista lateral, CM.S. Núñez-Novas. B, mapa de distribución.

Chilonatalus micropus. Nativa. Especie insectívora y obligatoria de cuevas. Es la especie más rara de la isla. No se conoce claramente el tamaño de sus colonias. Fue menos abundante que $N$. major en los muestreos y en las colecciones científicas. En algunas de las localidades muestreadas se capturó un máximo de dos individuos. Suele compartir refugio con $N$. major, por lo que presenta las mismas características de cuevas inundadas y cuerpos de agua cercanos. Es una especie nocturna, saliendo alrededor de las 21:00 h. Presentan una coloración grisácea clara con algunas tonalidades amarillentas. 


\section{Vespertiolinidae}

Las dos especies que se encuentran en La Española se alimentan de insectos, los que cazan al vuelo. Habitan en la entrada de las cuevas o en árboles.
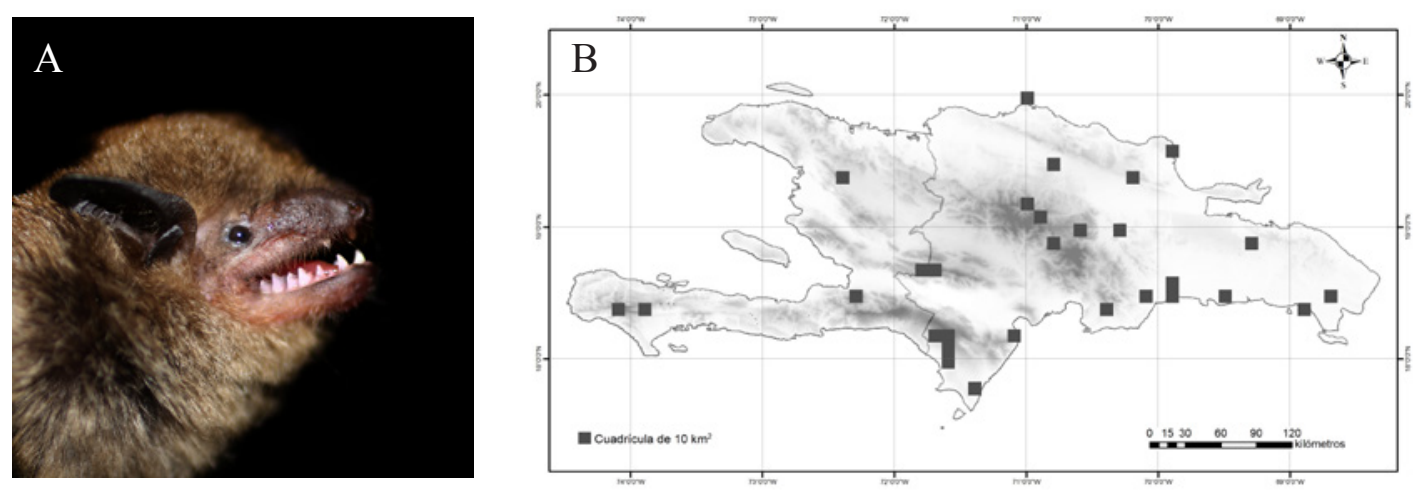

Figura 21. Eptesicus fuscus. A, vista lateral, CM.S. Núñez-Novas. B, mapa de distribución.

Eptesicus fuscus. Nativa. Especie insectívora y generalista. Habita en la entrada y zonas ventiladas de las cuevas. Se puede encontrar de forma solitaria o formando colonias de docenas. Se registró una colonia de unos 25 individuos en un abrigo rocoso en Santo Domingo. Es poco abundante en los muestreos y en las colecciones. Posee una coloración negruzca.
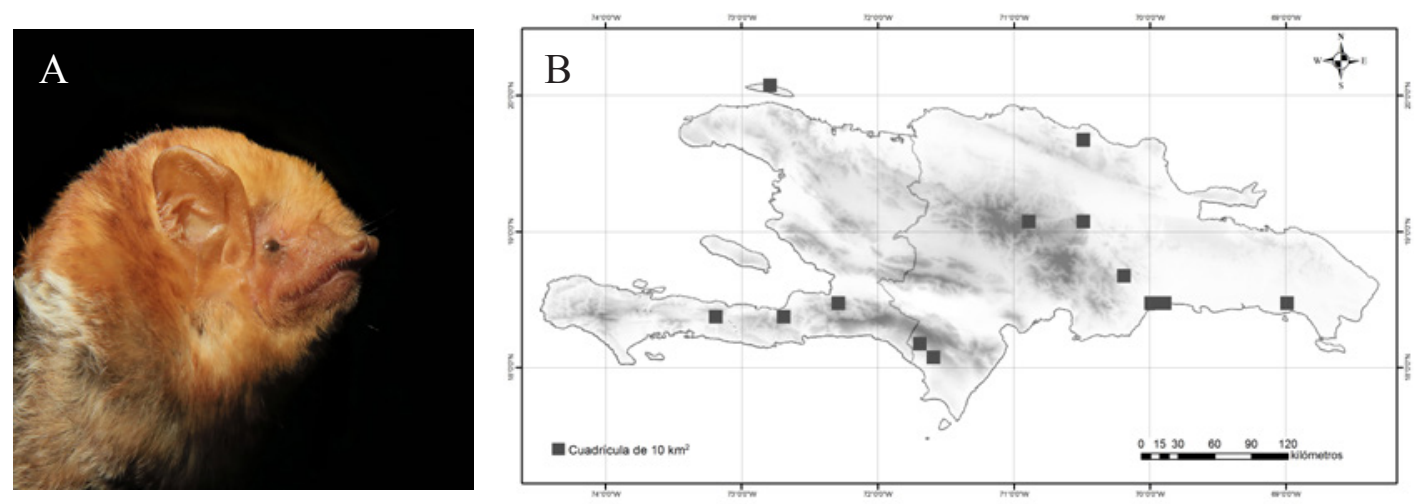

Figura 22. Lasiurus minor. A, vista lateral, CM.S. Núñez-Novas. B, mapa de distribución.

Lasiurus minor. Nativa. Especie insectívora y de hábitos arborícolas. Es muy común en zonas boscosas, prefiere lugares con fuentes de agua cercanas. El tamaño de sus colonias es desconocido, ya que no se ha podido observar en sus lugares de reposo. Se han encontrado lugares donde resulta ser la especie más abundante, como es en la sierra de Bahoruco, donde en una charca artificial, se contabilizaron más de 30 individuos, sin contar los que al caer en las redes escapaban y los que se observaban evitándolas. Es una especie nocturna siendo capturada alrededor de las 20:00 h. Presenta una coloración rojiza. 
Tabla I. Datos morfométricos $(\mathrm{mm})$ por especie

\begin{tabular}{|c|c|c|c|c|c|c|}
\hline Especie & Mínimo & Máximo & Promedio & $\begin{array}{c}\text { Desviación } \\
\text { estándar }\end{array}$ & $\begin{array}{c}\text { Coeficiente de } \\
\text { variación }\end{array}$ & $\mathbf{N}$ individuos \\
\hline \multicolumn{2}{|c|}{ Noctilio leporinus } & & & & & 48 \\
\hline LT & 108 & 134.00 & 123.06 & 5.30 & 4.31 & \\
\hline LC & 20 & 32.00 & 26.44 & 2.90 & 10.98 & \\
\hline LP & 21 & 34.00 & 27.15 & 4.17 & 15.37 & \\
\hline LA & 81 & 90.00 & 86.32 & 2.16 & 2.50 & \\
\hline LO & 24 & 33.00 & 27.94 & 2.12 & 7.60 & \\
\hline LTr & 6 & 7.00 & 6.50 & 0.71 & 10.88 & \\
\hline $\mathrm{g}$ & 54 & 86.00 & 69.64 & 9.17 & 13.16 & \\
\hline \multicolumn{2}{|c|}{ Artibeus jamaicensis } & & & & & 180 \\
\hline LT & 60 & 108.00 & 82.54 & 9.29 & 11.25 & \\
\hline LC & 0 & 0.00 & 0.00 & 0.00 & 0.00 & \\
\hline LP & 7 & 19.00 & 12.74 & 2.44 & 19.17 & \\
\hline LA & 46.4 & 61.90 & 56.58 & 2.46 & 4.35 & \\
\hline LO & 8 & 23.00 & 18.16 & 2.65 & 14.62 & \\
\hline $\mathrm{LTr}$ & 3 & 10.00 & 5.85 & 1.31 & 22.41 & \\
\hline $\mathrm{g}$ & 19 & 61.00 & 36.82 & 8.55 & 23.21 & \\
\hline \multicolumn{2}{|c|}{ Brachyphylla pumila } & & & & & 48 \\
\hline LT & 69 & 102.00 & 83.01 & 8.19 & 9.87 & \\
\hline LC & 0 & 0 & 0.00 & 0.00 & 0.00 & \\
\hline LP & 10 & 18.00 & 14.23 & 2.05 & 14.40 & \\
\hline LA & 52 & 63.00 & 57.73 & 2.16 & 3.75 & \\
\hline LO & 12 & 22.00 & 18.40 & 2.62 & 14.22 & \\
\hline $\mathrm{LTr}$ & 5 & 9.00 & 6.79 & 0.98 & 14.44 & \\
\hline $\mathrm{g}$ & 23.4 & 65.00 & 31.87 & 8.30 & 26.05 & \\
\hline \multicolumn{2}{|c|}{ Phyllops falcatus } & & & & & 37 \\
\hline LT & 45 & 77.00 & 58.90 & 7.77 & 13.20 & \\
\hline LC & 0 & 0.00 & 0.00 & 0.00 & 0.00 & \\
\hline LP & 7 & 66.00 & 11.73 & 9.44 & 80.49 & \\
\hline LA & 38 & 45.00 & 41.89 & 1.60 & 3.81 & \\
\hline LO & 12 & 19.00 & 14.82 & 2.15 & 14.48 & \\
\hline $\mathrm{LTr}$ & 4 & 8.00 & 6.54 & 1.39 & 21.28 & \\
\hline g & 11.5 & 23.00 & 16.43 & 3.43 & 20.90 & \\
\hline \multicolumn{2}{|c|}{ Macrotus waterhousii } & & & & & 148 \\
\hline LT & 75 & 112.00 & 94.90 & 6.99 & 7.36 & \\
\hline LC & 20 & 40.00 & 31.39 & 3.63 & 11.55 & \\
\hline
\end{tabular}




\begin{tabular}{|c|c|c|c|c|c|c|}
\hline Especie & Mínimo & Máximo & Promedio & $\begin{array}{l}\text { Desviación } \\
\text { estándar }\end{array}$ & $\begin{array}{c}\text { Coeficiente de } \\
\text { variación }\end{array}$ & $\mathrm{N}$ individuos \\
\hline LP & 7 & 18.00 & 11.44 & 2.13 & 18.60 & \\
\hline LA & 38 & 57.00 & 52.66 & 2.38 & 4.52 & \\
\hline LO & 13 & 35.00 & 26.10 & 3.39 & 13.00 & \\
\hline LTr & 6 & 13.00 & 9.76 & 1.74 & 17.87 & \\
\hline g & 8 & 37.00 & 18.26 & 5.22 & 28.59 & \\
\hline \multicolumn{2}{|c|}{ Monophyllus redmani } & & & & & 71 \\
\hline LT & 53 & 74.00 & 65.59 & 3.85 & 5.87 & \\
\hline LC & 5 & 12.00 & 9.13 & 1.39 & 15.24 & \\
\hline LP & 5.3 & 14.00 & 9.27 & 2.37 & 25.61 & \\
\hline LA & 37 & 42.00 & 39.58 & 1.11 & 2.79 & \\
\hline LO & 6 & 14.00 & 11.69 & 1.69 & 14.46 & \\
\hline $\mathrm{LTr}$ & 2 & 5.00 & 2.93 & 1.00 & 34.09 & \\
\hline $\mathrm{g}$ & 8.4 & 13.00 & 10.98 & 1.17 & 10.66 & \\
\hline \multicolumn{2}{|c|}{ Erophylla bombifrons } & & & & & 61 \\
\hline LT & 55 & 85.00 & 72.90 & 4.61 & 6.33 & \\
\hline LC & 9 & 16.50 & 12.64 & 1.76 & 13.96 & \\
\hline LP & 8 & 18.00 & 11.28 & 2.13 & 18.87 & \\
\hline LA & 42 & 51.00 & 47.65 & 1.96 & 4.12 & \\
\hline LO & 10 & 19.00 & 15.08 & 1.83 & 12.11 & \\
\hline LTr & 4 & 8.00 & 5.31 & 1.05 & 19.75 & \\
\hline $\mathrm{g}$ & 7 & 30.00 & 14.30 & 4.59 & 32.07 & \\
\hline \multicolumn{2}{|c|}{ Phyllonycteris poeyi } & & & & & 61 \\
\hline LT & 55 & 85.00 & 72.90 & 4.61 & 6.33 & \\
\hline $\mathrm{LC}$ & 9 & 16.50 & 12.64 & 1.76 & 13.96 & \\
\hline LP & 8 & 18.00 & 11.28 & 2.13 & 18.87 & \\
\hline LA & 42 & 51.00 & 47.65 & 1.96 & 4.12 & \\
\hline LO & 10 & 19.00 & 15.08 & 1.83 & 12.11 & \\
\hline $\mathrm{LTr}$ & 4 & 8.00 & 5.31 & 1.05 & 19.75 & \\
\hline $\mathrm{g}$ & 7 & 30.00 & 14.30 & 4.59 & 32.07 & \\
\hline \multicolumn{2}{|c|}{ Nyctinomops macrotis } & & & & & 13 \\
\hline LT & 112 & 136.00 & 123.85 & 5.90 & 4.76 & \\
\hline LC & 46 & 52.00 & 48.70 & 2.13 & 4.37 & \\
\hline LP & 7 & 10.00 & 8.08 & 0.76 & 9.40 & \\
\hline LA & 55 & 61.00 & 57.79 & 1.78 & 3.08 & \\
\hline LO & 22 & 29.00 & 24.46 & 1.71 & 7.00 & \\
\hline $\mathrm{LTr}$ & 2 & 5.00 & 3.31 & 1.22 & 36.92 & \\
\hline g & 15 & 26.00 & 21.14 & 2.80 & 13.22 & \\
\hline
\end{tabular}


Tabla I (continuación)

\begin{tabular}{|c|c|c|c|c|c|c|}
\hline Especie & Mínimo & Máximo & Promedio & $\begin{array}{l}\text { Desviación } \\
\text { estándar }\end{array}$ & $\begin{array}{c}\text { Coeficiente de } \\
\text { variación }\end{array}$ & $\mathbf{N}$ individuos \\
\hline \multicolumn{2}{|c|}{ Tadarida brasiliensis } & & & & & 69 \\
\hline LT & 79 & 93.00 & 85.99 & 2.82 & 3.28 & \\
\hline $\mathrm{LC}$ & 27.2 & 36.00 & 31.42 & 2.62 & 8.35 & \\
\hline LP & 4 & 11.00 & 6.74 & 1.72 & 25.52 & \\
\hline LA & 38 & 43.00 & 40.44 & 1.16 & 2.88 & \\
\hline LO & 9.4 & 18.00 & 14.98 & 2.35 & 15.71 & \\
\hline LTr & 2 & 5.00 & 3.71 & 0.78 & 21.10 & \\
\hline $\mathrm{g}$ & 4 & 11.00 & 7.37 & 1.17 & 15.90 & \\
\hline \multicolumn{2}{|c|}{ Molossus molossus } & & & & & 94 \\
\hline LT & 85 & 104.00 & 93.13 & 4.17 & 4.48 & \\
\hline $\mathrm{LC}$ & 29 & 42.00 & 33.63 & 2.00 & 5.96 & \\
\hline LP & 4 & 12.00 & 7.76 & 2.22 & 28.65 & \\
\hline LA & 37 & 40.00 & 38.53 & 0.64 & 1.66 & \\
\hline LO & 10 & 17.00 & 12.02 & 1.43 & 11.87 & \\
\hline $\mathrm{LTr}$ & 3 & 5.00 & 3.52 & 0.55 & 15.68 & \\
\hline $\mathrm{g}$ & 6.5 & 14.50 & 10.84 & 1.99 & 18.38 & \\
\hline \multicolumn{2}{|c|}{ Mormoops blainvillei } & & & & & 39 \\
\hline LT & 72 & 86.00 & 81.62 & 2.60 & 3.19 & \\
\hline $\mathrm{LC}$ & 21 & 33.00 & 29.00 & 2.72 & 9.38 & \\
\hline LP & 4 & 10.00 & 6.33 & 1.36 & 21.53 & \\
\hline LA & 41 & 49.10 & 46.40 & 1.45 & 3.12 & \\
\hline LO & 9 & 18.00 & 13.49 & 1.73 & 12.83 & \\
\hline $\mathrm{LTr}$ & 2.5 & 8.00 & 4.23 & 1.28 & 30.22 & \\
\hline $\mathrm{g}$ & 7 & 11.00 & 8.87 & 1.14 & 12.81 & \\
\hline \multicolumn{2}{|c|}{ Pteronotus parnellii } & & & & & 59 \\
\hline LT & 56 & 102.00 & 74.68 & 8.95 & 11.99 & \\
\hline $\mathrm{LC}$ & 10 & 30.00 & 18.57 & 4.03 & 21.69 & \\
\hline LP & 6 & 13.00 & 10.00 & 1.63 & 16.27 & \\
\hline LA & 39.7 & 52.00 & 49.02 & 2.28 & 4.66 & \\
\hline LO & 12 & 22.00 & 16.54 & 2.82 & 17.07 & \\
\hline $\mathrm{LTr}$ & 3 & 6.00 & 4.26 & 0.75 & 17.64 & \\
\hline $\mathrm{g}$ & 5 & 18.00 & 11.35 & 2.59 & 22.81 & \\
\hline \multicolumn{2}{|c|}{ Pteronotus quadridens } & & & & & 55 \\
\hline LT & 50.8 & 68.00 & 62.80 & 3.34 & 5.32 & \\
\hline $\mathrm{LC}$ & 15 & 25.00 & 19.16 & 1.52 & 7.92 & \\
\hline LP & 5 & 14.00 & 9.27 & 1.57 & 16.92 & \\
\hline LA & 34 & 40.00 & 38.20 & 1.74 & 4.55 & \\
\hline
\end{tabular}




\begin{tabular}{|c|c|c|c|c|c|c|}
\hline Especie & Mínimo & Máximo & Promedio & $\begin{array}{l}\text { Desviación } \\
\text { estándar }\end{array}$ & $\begin{array}{c}\text { Coeficiente de } \\
\text { variación }\end{array}$ & $\mathbf{N}$ individuos \\
\hline LO & 10 & 34.00 & 15.72 & 2.88 & 18.35 & \\
\hline $\mathrm{LTr}$ & 3.5 & 7.00 & 4.69 & 1.44 & 30.67 & \\
\hline $\mathrm{g}$ & 4.5 & 7.00 & 5.80 & 0.97 & 16.69 & \\
\hline \multicolumn{2}{|c|}{ Natalus major } & & & & & 31 \\
\hline LT & 102 & 110.00 & 107.38 & 2.97 & 2.77 & \\
\hline LC & 48 & 59.00 & 54.95 & 2.92 & 5.32 & \\
\hline LP & 2 & 11.00 & 8.66 & 1.88 & 21.67 & \\
\hline LA & 40.1 & 49.00 & 42.86 & 1.78 & 4.15 & \\
\hline LO & 14 & 18.00 & 15.95 & 1.07 & 6.72 & \\
\hline $\mathrm{LTr}$ & 3 & 6.50 & 4.65 & 0.97 & 20.84 & \\
\hline g & 5 & 9.00 & 7.77 & 0.93 & 11.95 & \\
\hline \multicolumn{2}{|c|}{ Chilonatalus microtus } & & & & & 8 \\
\hline LT & 70.6 & 96.00 & 84.70 & 9.88 & 11.66 & \\
\hline LC & 42 & 55.00 & 47.68 & 5.37 & 11.27 & \\
\hline LP & 4.5 & 7.00 & 5.56 & 0.82 & 14.76 & \\
\hline LA & 32.9 & 42.00 & 36.49 & 4.58 & 12.55 & \\
\hline LO & 11 & 16.00 & 12.53 & 1.58 & 12.60 & \\
\hline $\mathrm{LTr}$ & 3 & 6.00 & 4.00 & 1.00 & 25.00 & \\
\hline g & 3 & 3.00 & 3.00 & 0.00 & 0.00 & \\
\hline \multicolumn{2}{|c|}{ Eptesicus fuscus } & & & & & 19 \\
\hline LT & 97.4 & 111.00 & 106.39 & 3.14 & 2.95 & \\
\hline $\mathrm{LC}$ & 40 & 47.00 & 44.29 & 1.85 & 4.18 & \\
\hline LP & 4 & 9.00 & 7.68 & 1.06 & 13.75 & \\
\hline LA & 44 & 51.00 & 47.74 & 1.53 & 3.20 & \\
\hline LO & 12 & 17.00 & 15.21 & 1.32 & 8.65 & \\
\hline $\mathrm{LTr}$ & 6 & 8.00 & 6.67 & 0.59 & 8.91 & \\
\hline $\mathrm{g}$ & 9.5 & 16.30 & 13.41 & 2.07 & 15.44 & \\
\hline \multicolumn{2}{|c|}{ Lasiurus minor } & & & & & 31 \\
\hline LT & 79 & 106.00 & 97.03 & 6.06 & 6.25 & \\
\hline LC & 30 & 46.00 & 41.77 & 4.43 & 10.59 & \\
\hline LP & 3 & 8.00 & 6.42 & 1.03 & 15.97 & \\
\hline LA & 37 & 43.00 & 40.55 & 1.50 & 3.71 & \\
\hline LO & 7 & 14.00 & 10.80 & 1.30 & 12.01 & \\
\hline $\mathrm{LTr}$ & 4 & 7.00 & 5.40 & 0.93 & 17.26 & \\
\hline $\mathrm{g}$ & 7 & 17.00 & 10.15 & 2.95 & 29.04 & \\
\hline Total & & & & & & 1072 \\
\hline
\end{tabular}




\section{AGRADECIMIENTOS}

A1 Museo Nacional de Historia Natural "Prof. Eugenio de Jesús Marcano” por todo el apoyo logístico y económico que posibilitó la realización del trabajo. A IdeasWild por la donación de la cámara que permitió realizar parte de las fotografías. A Erik Calderon-Davila, Rodrigo Medellín y Ángel Soto-Centeno por la donación de sus fotos. A Juan Carlos Núñez por la edición de las fotos y la elaboración de los esquemas. A Carlos Suriel y Hodali Almonte por sus correcciones. A la Relcom por su disposición y colaboración. A los que prestaron su colaboración en las distintas etapas del trabajo: Amelia Mateo, Ángel Soto, Armando Rodríguez-Durán, Arturo León, Carlos Mancina, Cristian Marte, Eveling Gabot, Joel D'Oleo, Jorge Carrera, Juan Almonte, Gabriel de los Santos, Mimo D'Oleo.

\section{LITERATURA CITADA}

Allen, G. M. 1911. Mammals of the West Indies. Bulletin of the Museum of Comparative Zoology, 54: 175-263.

Allen, G. M. 1917. Two undescribed West Indian bats. Proceedings of the Biological Society of Washington, 30: 165-170.

Allen, J. 1908. Mammalogical notes. II. Bats from the island of San Domingo. Bulletin of the American Museum of Natural History, 24: 580-582.

Baker, R. J. y H. H. Genoways. 1978. Zoogeography of Antillean bats. Special Publication, Academy of Natural Sciences of Philadelphia, 13: 53-97.

Baker, R. J., J. A. Groen, y R. D. Owen. 1984. Field key to Antillean bats. Occasional Papers, Museum of Texas Tech University, 94: 1-18.

Cassá, R. 1974. Los taínos de la Española, Editora de la Universidad Autónoma de Santo Domingo, $272 \mathrm{pp}$.

Dávalos, L. M. 2004. Phylogeny and biogeography of Caribbean mammals. Biological Journal of the Linnean Society, 81: 373-394.

Dávalos, L. M. 2005. Molecular phylogeny of funnel-eared bats (Chiroptera: Natalidae), with notes on biogeography and conservation. Molecular Phylogenetics and Evolution, 37: 91-103.

Dávalos, L. M. 2010. Earth history and the evolution of Caribbean bats. En: T. H. Fleming y P. A. Racey (Eds.), Island bats: ecology, evolution, and conservation. Chicago: University of Chicago Press.

Dávalos, L. M., W. C. Lancaster, M. S. Núñez-Novas, Y. M. León, B. Lei, J. Flanders y A. L. Russell. 2018. A coalescent-based estimator of genetic drift, and acoustic divergence in the Pteronotus parnellii species complex. Heredity. DOI: 10.1038/s41437-018-0129-3.

Elliot, D. G. 1905. Descriptions of apparently new species and subspecies of mammals from Mexico and Santo Domingo. Proceedings of the Biological Society of Washington, 18: 233-236.

Fabián-Calcagno, N. 2004. Murciélagos. Cronología de las clasificaciones y reacciones a virus rábico de República Dominicana. Atajo, revista sobre Ciencia, Sociedad y Medio Ambiente, 3: 10-12. 
Fabián-Calcagno, N. 2011. Primer reporte en Républica Dominicana del murciélago Tonatia silvicola (murciélago de orejas redondas). Verdor, 24: 440-446.

Figueroa-Espinosa, A. A. y M. Vicente-Olaverria. 1990. Investigación de los murciélagos de la zona este de la República Dominicana como reactores a virus rábico. Tesis doctoral, Faculdad de Ciencias Agronómicas y Veterinarias, Universidad Autónoma de Santo Domingo.

Flanders, J. R., L. Yohe, S. J. Rossiter y L. M. Dávalos. 2014. Fiel key to the bats of Hispaniola. [Accessed 15/02/2018].

Fleming, T. H. 1982. Parallel trends in the species diversity of West Indian bats and birds. Oecologia, 53: 56-60.

García-Marcano, N. 2003. Presencia de Murciélagos Molossus molossus en el municipio, Santo Domingo Este. El Correo Ecológico [Online, accedido 15/02/2018].

García-Marcano, N. 2005a. Cueva los Patos, Barahona hábitat de importancia para los murciélagos. El Correo Ecológico [Online, accedido 15/02/2018].

García-Marcano, N. 2005b. Murciélagos de las cuevas del litoral costero del parque nacional Los Haitises. El Correo Ecológico [Online, accedido 15/02/2018].

García-Marcano, N. 2006a. Comportamiento alimentario observado en el murciélago pescador (Noctilio leporinus mastivus). El Correo Ecológico [Online, accedido 15/02/2018].

García-Marcano, N. 2006b. Murciélagos encontrados en área costera del Parque Nacional Los Haitises, Sabana de La Mar. El Correo Ecológico [Online, accedido 15/02/2018].

García-Marcano, N. 2011. Reserva Científica Salcedoa levantamiento de información mastofauna. Informe Ministerio de Medio Ambiente y Recursos Naturales.

García-Marcano, N. y G. Dominici. 2002a. Habitantes de la Oscuridad I Murciélagos de la República Dominicana). Atajo, revista sobre Ciencia, Sociedad y Medio Ambiente, 1: 20-21.

García-Marcano, N. y G. Dominici. 2002b. Habitantes de la Oscuridad II Murciélagos de la República Dominicana). Atajo, revista sobre Ciencia, Sociedad y Medio Ambiente, 1: 20-21.

García-Marcano, N., I. Mota, D. Flores, L. Familia y C. Esquea. 2011. Informe sobre levantamiento de información cueva La Iglesia o el Soco y entorno, San Pedro de Macorís. Informe Ministerio de Medio Ambiente y Recursos Naturales.

Goldberg, A., A. L. Russell, Y. Leon, M. S. Núñez y L. M. Dávalos. 2010. Cheek Swabs as an Alternative to Wing Punctures for DNA Sampling in the Field. 40th Annual Symposium on Bat Research. Denver.

Gómez-Gonzáles, D. y H. Nevarez-Rivera. 1987. Investigación de los murciélagos de la zona este de la República Dominicana como reactores a virus rábico. Tesis doctoral, Faculdad de Ciencias Agronómicas y Veterinarias, Universidad Autónoma de Santo Domingo.

Gundlach, J. 1877. Contribución a la mamalogía cubana, Habana, G. Montiel y Comp. 53 pp.

Hershkovitz, P. 1951. Mammals from British Honduras, Mexico, Jamaica and Haiti. Fieldiana Zoology, 31: 547-569. 
Klingener, D., H. H. Genoways y R. J. Baker. 1978. Bats from southern Haiti. Annals of Carnegie Museum, 47: 81-99.

Koopman, K. F. 1989. A review and analysis of the bats of the West Indies. En: C. A. Woods (Ed.), Biogeography of the West Indies, past, present, and future. Gainesville, Florida: Sandhill Crane Press, Gainsville, Florida, 878 pp.

Lim, B. K., L. O. Loureiro, N. S. Upham y J. L. Brocca. 2017. Phylogeography of Dominican Republic bats and implications for systematic relationships in the Neotropics. Journal of Mammalogy, 98: 986-993.

Mcfarlane, D. A. 1989. Patterns of species co-occurrence in the Antillean bat fauna. Mammalia, 53: 59-66.

Mcfarlane, D. A. 1991. The species-genus relationship in Antillean bat communities. Mammalia, 55: $363-370$.

Miller, G. S. 1918. Three new bats from Haiti and Santo Domingo. Proceedings of the Biological Society of Washington, 31: 39-40.

Miller, G. S. 1929. A second collection of mammals from caves near St. Michel, Haiti. Smithsonian Miscellaneous Contributions, 81: 1-30.

Miller, G. S. 1930. Three small collections of mammals from Hispaniola. Smithsonian Miscellaneous Contributions, 82: 1-15.

Núñez-Novas, M. S. 2010. Los Murciélagos. Parque Mirador Sur Flora y Fauna. Impreso en República Dominicana, 95 pp.

Núñez-Novas, M. S. 2014. Distribución espacial de las poblaciones de murciélagos (Chiroptera Blumenbach, 1779) en la isla La Española. Tesis de maestría, Universidad Autónoma de Madrid y Universidad Complutense de Madrid.

Núñez-Novas, M. S. y Y. M. León. 2011. Análisis de la colección de murciélagos (Mammalia: Chiroptera) del Museo Nacional de Historia Natural de Santo Domingo. Novitates Caribaea, 4: 109-119.

Núñez-Novas, M. S., Y. M. León, J. Mateo y L. M. Dávalos. 2014. Horas de éxodo y estacionalidad de los murciélagos en cuatro cuevas de República Dominicana. Novitates Caribaea, 7: 83-94.

Núñez-Novas, M. S., León, Y. M., Mateo, J. y Dávalos, L. M. 2016. Records of the cave-dwelling bats (Mammalia: Chiroptera) of Hispaniola with an examination of seasonal variation in diversity. Acta Chiropterologica, 18: 269-279.

Ottenwalder, J. A. 1978. Hallan murciélago pescador en la isla Beata [Online]. Available: http:// www.jmarcano.com/ecohis/np/np78d.html [Accessed 05/07/2013].

Ottenwalder, J. A. 1979. Murciélagos del Lago Enriquillo [Online]. Available: http://www. jmarcano.com/ecohis/np/np79c.html [Accessed 05/07/2013].

Ottenwalder, J. 1981. Murciélagos de la Isla Beata. Contribuciones Ocasionales, Museo Nacional de Historia Natural de Santo Domingo, 1: 1-7. 
Ottenwalder, J. A. 1995. Evaluación de la biodiversidad de la Reserva Antropológica Cuevas el Pomier, San Cristóbal. Informe Técnico Final preparado para el Programa de Pequeños Subsidios a ONGs del FMAM (GEF/Small Grants Program), Fondo para el Medio Ambiente Mundial, República Dominicana (Project leader and PI). Santo Domingo, 110 pp.

Ottenwalder, J. A. y H. H. Genoways. 1982. Systematic review of the Antillean bats of the Natalus micropus-complex (Chiroptera: Natalidae). Annals of Carnegie Museum, 51: 17-38.

Pine, R. H. 1980. Keys to the bats of Jamaica, Hispaniola and Puerto Rico based on gross external characters. Caribbean Journal of Science, 15 (3-4), 9-11.

Rodríguez-Durán, A. y K. Christenson. 2012. Breviario sobre los murciélagos de Puerto Rico, La Española e Islas Vírgenes, Universidad Interamericana de Puerto Rico.

Rodríguez Durán, A. y T. H. Kunz. 2001. Biogeography of West Indian bats: an ecological perspective. En: C. A. Woods y F. E. Sergile (Eds.), Biogeography of the West Indies: Patterns and perspectives. 2nd ed. Boca Raton: CRC Press, 896 pp.

Silva-Taboada, G. 1979. Los murciélagos de Cuba, La Habana, Editorial Academia, 423 pp.

Simmons, N. B. 2005. Order Chiroptera. En: D. E. Wilson y D. M. Reeder (Eds.), Mammal species of the World: a taxonomic and geographic reference. 3rd ed., Vol. 1, 2. Johns Hopkins University Press, Baltimore, USA, 2142 pp.

Simpson, G. G. 1956. Zoogeography of West Indian land mammals. American Museum Novitates, 1759: 1-28.

Soto-Centeno, J. A., M. O’brien y N. B. Simmons. 2015. The importance of late Quaternary climate change and karst on distributions of Caribbean mormoopid bats. American Museum Novitates, 1-32.

Soto-Centeno, J. A., N. B. Simmons y D. W. Steadman. 2017. The bat community of Haiti and evidence for its long-term persistence at high elevations. PloS one, 12, e0178066.

Soto-Centeno, J. A. y D. W. Steadman. 2015. Fossils reject climate change as the cause of extinction of Caribbean bats. Scientific reports, 5: 1-7.

Tejedor, A., V. C. Tavares y D. Rodríguez-Hernández, 2005a. New records of hot-cave bats from Cuba and the Dominican Republic. Boletín de la Sociedad Venezolana de Espeleología, 39:10-15.

Tejedor, A., V. D. C. Tavares, y G. Silva-Taboada. 2005b. Taxonomic revision of Greater Antillean bats of the genus Natalus. American Museum Novitates, 3493: 1-22.

Varona, L. S. 1974. Catálogo de los mamíferos vivientes y extinguidos de las Antillas, Havana, Academia de Ciencias de Cuba, 139 pp.

Velazco, P. M., H. O’neill, G. F. Gunnell, S. B. Cooke, R. Rimoli, A. L. Rosenberger y N. B. Simmons. 2013. Quaternary bat diversity in the Dominican Republic. American Museum Novitates, 3779: 1-20. 